OPEN ACCESS

Edited by:

Alexandre Corthay,

Oslo University Hospital, Norway

Reviewed by:

Anne-Catherine Raby,

Cardiff University, United Kingdom

Neda Barjesteh,

Université de Montréal, Canada

*Correspondence:

Sven Wehner

sven.wehner@ukbonn.de

Specialty section:

This article was submitted to

Molecular Innate Immunity,

a section of the journal

Frontiers in Immunology

Received: 07 July 2020

Accepted: 27 November 2020

Published: 13 January 2021

Citation:

Enderes J, Mallesh S, Schneider R,

Hupa KJ, Lysson M, Schneiker B, Händler K, Schlotmann B, Günther $P$,

Schultze JL, Kalff JC and Wehner S (2021) A Population of Radio-Resistant

Macrophages in the Deep

Myenteric Plexus Contributes to

Postoperative lleus Via Toll-Like

Receptor 3 Signaling.

Front. Immunol. 11:581111.

doi: 10.3389/fimmu.2020.581111

\section{A Population of Radio-Resistant Macrophages in the Deep Myenteric Plexus Contributes to Postoperative Ileus Via Toll-Like Receptor 3 Signaling}

\author{
Jana Enderes ${ }^{1}$, Shilpashree Mallesh ${ }^{1}$, Reiner Schneider ${ }^{1}$, Kristof J. Hupa ${ }^{1}$, \\ Mariola Lysson ${ }^{1}$, Bianca Schneiker ${ }^{1}$, Kristian Händler ${ }^{2}$, Balthasar Schlotmann ${ }^{3}$, \\ Patrick Günther ${ }^{2,3}$, Joachim L. Schultze ${ }^{2,3,4}$, Jörg C. Kalff ${ }^{1}$ and Sven Wehner ${ }^{1 *}$ \\ 1 Department of Surgery, Division of Immune Pathophysiology, University Hospital Bonn, Bonn, Germany, 2 PRECISE \\ Platform for Single Cell Genomics and Epigenomics, German Center for Neurodegenerative Diseases (DZNE), University of \\ Bonn, Bonn, Germany, ${ }^{3}$ Genomics and Immunoregulation, Life \& Medical Sciences (LIMES) Institute, University of Bonn, \\ Bonn, Germany, ${ }^{4}$ Systems Medicine, German Center for Neurodegenerative Diseases (DZNE), Bonn, Germany
}

Postoperative ileus (POI) is triggered by an innate immune response in the muscularis externa (ME) and is accompanied by bacterial translocation. Bacteria can trigger an innate immune response via toll-like receptor (TLR) activation, but the latter's contribution to POI has been disproved for several TLRs, including TLR2 and TLR4. Herein we investigated the role of double-stranded RNA detection via TLR3 and TIR-domain-containing adapterinducing interferon- $\beta$ (TRIF) signaling pathway in POI. POI was induced by small bowel intestinal manipulation in $\mathrm{wt} \mathrm{TRIF}^{-/-}, \mathrm{TLR}^{-/-}$, type I interferon receptor ${ }^{-/-}$and interferon- $\beta$ reporter mice, all on C57BL/6 background, and $\mathrm{POI}$ severity was quantified by gene expression analysis, gastrointestinal transit and leukocyte extravasation into the ME. TRIF/ TLR3 deficiency reduced postoperative ME inflammation and prevented POI. With bone marrow transplantation, RNA-sequencing, flow cytometry and immunohistochemistry we revealed a distinct TLR3-expressing radio-resistant $\mathrm{MHCl}{ }^{\mathrm{hi}} \mathrm{CX} 3 \mathrm{CR} 1^{-} \mathrm{IBA}-1^{+}$resident macrophage population within the deep myenteric plexus. TLR3 deficiency in these cells, but not in $\mathrm{MHCll}{ }^{\text {hi }} \mathrm{CX} 3 \mathrm{CR}^{+}{ }^{+}$macrophages, reduced cytokine expression in $\mathrm{POI}$. While this might not be an exclusive macrophage-privileged pathway, the TLR3/TRIF axis contributes to proinflammatory cytokine production in $\mathrm{MHCl}{ }^{\text {hi }} \mathrm{CX} 3 \mathrm{CR} 1^{-} \mathrm{IBA}-1^{+}$ macrophages during POI. Deficiency in TLR3/TRIF protects mice from POI. These data suggest that TLR3 antagonism may prevent POI in humans.

Keywords: postoperative ileus, TLR3, TRIF, macrophages, innate immune response

Abbreviations: CX3CR1, CX3C chemokine receptor 1; DAMPS, damage-associated molecular patterns, dsRNA, double stranded RNA; DC, dendritic cells; GIT, gastrointestinal transit; GI tract, gastrointestinal tract; GC, geometric center; IM, intestinal manipulation; ISGs, IFN-stimulated genes; ME, muscularis externa; MPO, myeloperoxidase; POI, postoperative ileus; TLR, toll-like receptor; TRIF, TIR-domain-containing adapter-inducing interferon- $\beta$. 


\section{INTRODUCTION}

Postoperative ileus (POI) is a gastrointestinal dysmotility and a common consequence of abdominal surgery. Patients suffer from nausea and vomiting, abdominal pain and oral food intolerance, which causes prolonged hospital stay and is associated with increased health care costs (1). The pathophysiology of POI is multifactorial and involves activation of resident immunocytes and cells of the enteric nervous system within the muscularis externa (ME) during surgery. Upon activation, these cells release proinflammatory cytokines and chemokines which further trigger and maintain ME inflammation and recruitment of blood-derived leukocytes (2). Resident ME macrophages (3,4), dendritic cells (DC) $(5,6)$, and enteric glial cells $(7)$ were shown to be important contributors in the initial phase of this inflammatory process. Macrophages highly express the $\mathrm{CX} 3 \mathrm{C}$ chemokine receptor 1 (CX3CR1) (8) and show a prominent distribution within the intestinal musculature (9). Furthermore, they are self-maintaining and colonize distinct niches in the gut, and they are essential for intestinal homeostasis during which they can shape intestinal motility $(8,10)$.

Although crucial, the underlying molecular mechanisms of resident immunocyte activation during POI are still not fully understood. Possible triggers could be release of endogenous damage-associated molecular patterns (DAMPs) upon the surgical trauma as well as pathogen-associated molecular patterns that originate from luminal microbiota. Intestinal bacteria were shown to translocate into the ME and even disseminate to distant organs (11) due to a surgery-induced intestinal barrier dysfunction (12). The translocated bacteria exhibit multiple toll-like receptor (TLR) ligands and resident ME macrophages are known to express several TLRs (13). However, previous work from our group demonstrated that prominent TLRs, i.e., TLR2 and TLR4 (7), both detecting bacterial cell wall components as well as TLR9 were not involved in POI pathogenesis. While all the TLRs signal via the adapter molecule MyD88, TLR3 exclusively signals via the TIR-domain-containing adapter-inducing interferon- $\beta$ (TRIF). In contrast to TLR2 and TLR4, TLR3 is an intracellular receptor, located on the endosomal compartment, and activated by double stranded RNA (dsRNA). As TLR3 can also be expressed on phagosomes upon phagosomeendosome fusion (14) and was already described to detect damaged cells upon sterile radio trauma to the intestine or the skin $(15,16)$ we hypothesized that TLR3 might play a role in POI pathogenesis.

In the present manuscript, we investigated the role of the TLR3-TRIF pathway in several transgenic and knockout mouse models, revealed the relevant molecular mechanisms of TLR3 activation upon surgery and identified a resident macrophage population colonizing a distinct anatomical niche in the $\mathrm{ME}$ as a responsible cell population for TLR3 signaling during POI.

\section{METHODS}

\section{Animals}

Wildtype (wt) C57BL/6 mice were purchased from Janvier (Saint-Berthevin Cedex, France), TRIF ${ }^{/-}$mice (17), TLR3 ${ }^{-/-}$ mice (18), IFNAR ${ }^{-/-}$mice (19), IFN- $\beta \mathrm{luc}^{+/-}$mice (20), $\mathrm{CX} 3 \mathrm{CR} 1^{\mathrm{GFP} /+}$ mice (21), CX3CR $1^{\mathrm{GFP} /+} \times \mathrm{xLR} 3^{\mathrm{d} / \mathrm{d}}$ mice (own breeding) and $\mathrm{LysM}^{\text {cre+ }} ; \operatorname{ROSA} 26^{\mathrm{LSL}-\mathrm{eYFP}}(22)$, all on C57BL/6 background, were kept under specific pathogen-free conditions in the animal housing facility of the University of Bonn (Germany). Mice were acclimatized and cohoused with littermates in groups of up to five animals for one week after transportation from the vendor. Animal experiments were performed two to four times as indicated and with the indicated numbers of animals in female mice with a bodyweight between 20 to $25 \mathrm{~g}$. Whenever possible we performed the interventions of different genotypes (e.g. intestinal manipulation of $\mathrm{TLR}^{+/+}$and $\mathrm{TLR}^{-1-}$ ) on one day. Mice had free access to a standard diet chow and water ad libitum.

All animal experiments were performed according to the German Protection of Animals Act (TierSchG) and were approved by the governmental authority of North-Rhine Westfalia (LANUV).

\section{Generation of Bone Marrow Chimeric Mice}

Bone marrow transfer was used to create chimeric mice with a TLR3 deficiency either in the radio-sensitive circulating cells (wt $\mathrm{x} \mathrm{TLR}^{-/-}$chimera) or in the radio-resistant resident tissue cells $\left(\mathrm{TLR}^{-/-} \mathrm{x} \mathrm{wt}\right)$. Bone marrow cells were collected from the femur and tibia of wt or TLR3 ${ }^{-/-}$donor mice. A total of $1.2 \times 10^{7}$ cells were injected intravenously to 9-Gy irradiated host mice 6$7 \mathrm{~h}$ after irradiation. Four chimera groups were generated (wt $\mathrm{x}$ wt bone marrow, wt $\mathrm{x} \mathrm{TLR}^{-/-}$bone marrow, $\mathrm{TLR}^{-/-} \mathrm{x}$ wt bone marrow and $\mathrm{TLR}^{-/-} \mathrm{x} \mathrm{TLR}^{-/-}$bone marrow). To test if lethally irradiated $\mathrm{MHCII}^{\mathrm{hi}} \mathrm{CX} 3 \mathrm{CR} 1^{+}$and $\mathrm{MHCII}^{\text {hi }} \mathrm{CX} 3 \mathrm{CR} 1^{-}$cells are replaced by circulating monocytes we either lead-shielded or did not shield the abdomen of CX3CR $1^{\mathrm{GFP} /+}$ mice before 9-Gy irradiation and reconstituted them 6-7 h later with $1.2 \times 10^{7}$ bone marrow cells from the femur and tibia of $\mathrm{LysM}^{\text {cre+ }}$; ROSA $26^{\text {LSL-eYFP }}$ donor mice. Further analyses were performed 6-7 weeks after irradiation.

\section{Animal Model of Postoperative lleus}

POI was induced by a standardized intestinal manipulation (IM) procedure as described previously in detail ${ }^{3}$. In brief, Mice were anesthetized by inhalation of isoflurane (3\%-5\% isoflurane, 3-5 $\mathrm{L} / \mathrm{min}$ flow), placed in a spine position and injected with Tramadol $10 \mathrm{mg} / \mathrm{kg}$ BW subcutaneously $5 \mathrm{~min}$ prior to surgery (as an additional analgesia postoperatively mice received Tramadol $1 \mathrm{mg} / \mathrm{ml}$ with drinking water). A midline incision of the skin measuring $1 \mathrm{~cm}$ and opening of the abdominal muscles and the peritoneum along the linea alba was performed. The small intestine was carefully eventrated, placed on a sterile tissue and smoothly rolled between two moist cotton swabs twice antegradely from the duodenum to the terminal ileum. The intestine was neither transected nor sutured. After this mechanical manipulation procedure, the small intestine was then carefully placed back into the abdominal cavity. Peritoneum and skin were closed by two layers of continuous sutures. For controls, either sham-operated or non-operated 
mice were used, as indicated. Sham operation was performed accordingly to the before mentioned IM procedure including the eventration of the small bowel out of the belly but without the mechanical manipulation. The intestine was replaced into the belly after the same duration the manipulation took in the IM group.

\section{Gastrointestinal Transit}

To analyze the effects of IM on gut motility gastrointestinal transit (GIT) was measured $24 \mathrm{~h}$ after IM as previously described (23). In brief, $22.5 \mathrm{~h}$ after manipulation mice were gavaged with $100 \mu \mathrm{l}$ FITC-labeled dextran $(70 \mathrm{kDa} ; 6.25 \mathrm{mg} / \mathrm{ml} /$ gavage $)$. After a fasting period of $90 \mathrm{~min}$ organs were harvested $24 \mathrm{~h}$ after IM and the intestinal tract from stomach to colon was divided into 15 segments. Luminal contents were washed out to determine the absorbance of dextran. The data were expressed as the percentage of activity per intestinal segment. GIT was calculated as the geometric center (GC) of distribution of the fluorescence marker using the following formula: $\mathrm{GC}=\Sigma$ (\% of total fluorescent signal per segment ${ }^{*}$ segment number $) \div 100$.

\section{Histochemical and Immunohistochemical Analysis}

Staining of $\mathrm{MPO}^{+}$monocytes and neutrophils was performed $24 \mathrm{~h}$ after IM. Midjejunal, mucosal-free muscularis whole mounts were fixed in ethanol (Applichem, Darmstadt, Germany) for $10 \mathrm{~min}$ and stained with Hanker-Yates reagent as described previously (24). $\mathrm{MPO}^{+}$cells were counted under a microscope (TE2000, Nikon, Düsseldorf, Germany) in 5 randomly chosen areas in each specimen at a $200 \mathrm{x}$ magnification and calculated as $\mathrm{MPO}^{+}$ cells $/ \mathrm{mm}^{2}$.

For immunofluorescence stainings for CX3CR1, MHCII, $\beta$ III-tubulin and IBA-1 midjejunal, mucosal-free muscularis whole mounts of either untreated CX3CR $1^{\mathrm{GFP} /+}$ or irradiated/ shielded or irradiated/non-shielded CX3CR $1^{\mathrm{GFP} /+}$ were fixed in 4\% PFA for $20 \mathrm{~min}$, permeabilized with $1 \%$ Triton X-1000 (Sigma), blocked with $5 \%$ donkey serum for $1 \mathrm{~h}$ and incubated with the appropriate antibodies at $4^{\circ} \mathrm{C}$ overnight. For antibodies used in this study see Table 1. All secondary antibodies were used at a 1:800 dilution and incubated for $1 \mathrm{~h}$ at room temperature. Nuclei were stained by HOECHST (Sigma), $3 \mu \mathrm{g} /$ $\mathrm{ml}$. Microscopic images were either taken by a TE2000 Nikon microscope at 200x magnification or on a Leica SP8 confocal microscope at 400x magnification.

\section{Preparation of Single-Cell Suspension of the Muscularis Externa}

Isolation of ME was achieved by sliding small bowel segments onto a glass rod and removing the outer muscularis circumferentially with moist cotton applicators. ME was then cut into fine pieces and digested with a $0.1 \%$ collagenase type II (Worthington Biochemical, Lakewood, NJ, USA) enzyme mixture, diluted in HBSS, containing $0.1 \mathrm{mg} / \mathrm{ml}$ DNase I (La Roche, Germany), $2.4 \mathrm{mg} / \mathrm{ml}$ Dispase II (La Roche, Germany), 1 $\mathrm{mg} / \mathrm{ml} \mathrm{BSA} \mathrm{(Applichem),} \mathrm{and} 0.7 \mathrm{mg} / \mathrm{ml}$ trypsin inhibitor (Applichem) for $40 \mathrm{~min}$ in a $37^{\circ} \mathrm{C}$ shaking water bath. Afterwards single cell suspension was obtained using a $70 \mu \mathrm{m}$ filter mesh.

\section{Isolation of Resident Muscularis Externa Macrophages}

For sorting of $\mathrm{MHCII}{ }^{\mathrm{hi}} \mathrm{CX} 3 \mathrm{CR} 1^{+}$and $\mathrm{MHCII}^{\mathrm{hi}+} \mathrm{CX} 3 \mathrm{CR} 1^{-}$cell populations, $\mathrm{ME}$ of six or nine mice per group was pooled in order to collect enough cells for further analyses. Single cell suspension was prepared as described above. After incubation with FcR-block (anti-CD16/32, BioLegend) cells were stained for $30 \mathrm{~min}$ at $4^{\circ} \mathrm{C}$ with the appropriate antibodies. For antibodies used in this study see Table 1. Cell sorting was performed on FACSAriaIII (BD Bioscience) and different cell populations were captured in PBS with 10\% FCS.

\section{Fluorescence Activated Cell Sorting}

Fluorescence activated cell sorting (FACS) analysis was performed on isolated ME of the small bowel 3 and $24 \mathrm{~h}$ after intestinal

TABLE 1 | List of antibodies used in this study.

\begin{tabular}{|c|c|c|c|c|}
\hline $\begin{array}{l}\text { Protein } \\
\text { Target }\end{array}$ & Dye/Dilution & Secondary antibody* & Use & Company \\
\hline CD45 & APC/1:200 & & FACS & eBioscience \\
\hline CD45 & Pacific blue/1:200 & & FACS & Biolegend \\
\hline CD45 & Су5/1:200 & & FACS & eBioscience \\
\hline $\mathrm{MHCll}$ & PE or PerCp-eF710/1:200 & & FACS & Biolegend \\
\hline Ly6C & PE/Cy7/1:200 & & FACS & Biolegend \\
\hline Ly6G & AlexaFluor647/1:300 & & FACS & eBioscience \\
\hline CD103 & $P E / 1: 200$ & & FACS & Biolegend \\
\hline CD11c & PE/Cy7/1:200 & & FACS & Biolegend \\
\hline CD11b & BV711/1:200 & & FACS & Biolegend \\
\hline anti-CD16/32 & 1:50 (blocking) & & FACS & Biolegend \\
\hline Near-IR & APC/Cy7/1:200 & & FACS & Thermo Fisher \\
\hline GFP & $1: 600$ & AlexaFluor488 & $\mathrm{IHC}$ & Novus biologicals \\
\hline $\mathrm{MHCl}$ & $1: 400$ & AlexaFluor647 or Cy3 & $\mathrm{HC}$ & BioLegend \\
\hline$\beta \mid I-T u b u l i n$ & $1: 600$ & Dylight405 & $\Vdash H C$ & BioLegend \\
\hline IBA-1 & $1: 200$ & AlexaFluor647 & $\mathrm{IHC}$ & Abcam \\
\hline
\end{tabular}

${ }^{*}$ All secondary antibodies were raised in donkey and used at 1:800 dilution. 
manipulation and in untreated control animals as well as in lethally irradiated shielded and non-shielded CX3CR $1^{\mathrm{GFP} /{ }^{+}} \mathrm{XLysM}^{\mathrm{cre}+}$; Rosa $26^{\mathrm{YFP}}$ chimera, respectively. Isolation of ME was achieved by sliding small bowel segments onto a glass rod, removing the outer muscularis circumferentially with moist cotton applicators and cutting the ME into fine pieces. ME was digested with a $0.1 \%$ collagenase type II (Worthington Biochemical, Lakewood, NJ, USA) enzyme mixture, diluted in HBSS, containing $0.1 \mathrm{mg} / \mathrm{ml}$ DNase I (La Roche, Germany), $2.4 \mathrm{mg} / \mathrm{ml}$ Dispase II (La Roche, Germany), $1 \mathrm{mg} / \mathrm{ml} \mathrm{BSA} \mathrm{(Applichem),} \mathrm{and} 0.7 \mathrm{mg} / \mathrm{ml}$ trypsin inhibitor (Applichem) for $40 \mathrm{~min}$ in a $37^{\circ} \mathrm{C}$ shaking water bath. Afterwards single cell suspension was obtained using a $70 \mu \mathrm{m}$ filter mesh. Cells were stained for $30 \mathrm{~min}$ at $4^{\circ} \mathrm{C}$ with the appropriate antibodies. For antibodies used in this study see Table 1. Flow cytometry analyses were performed on FACSCanto III (BD Biosciences) or with LSRFortessa ${ }^{\mathrm{TM}}$ (BD Biosciences) and Attune $^{\mathrm{TM}} \mathrm{NxT}$ (Invitrogen ${ }^{\mathrm{TM}}$ ), respectively, and data were analyzed with FlowJo software (Tree Star, Ashland, OR, USA).

\section{In Vivo Imaging System Analysis}

Bioluminescence was measured in IFN- $\beta l$ uc $^{+/-}$and wt mice 3, 6, and $24 \mathrm{~h}$ after intestinal manipulation. Another set of IFN$\beta_{\text {luc }}{ }^{+/-}$mice received an i.p. injection of $200 \mu \mathrm{g}$ PolyI:C/mouse (Invivogen) or vehicle (sterile endotoxin-free physiological water, $\mathrm{NaCl} 0.9 \%)$. Bioluminescence was analyzed using an InVivo Imaging System (IVIS) 200 system (Caliper LifeSciences) 5 min after i.p. injection of luciferin $(50 \mathrm{mM}$, Caliper Life Sciences) in PBS. Data analysis was performed with Living Image 2.50.1 software (Caliper LifeSciences).

\section{Enzyme-Linked Immunosorbent Assay}

ME was harvested 15 min after surgery and snap frozen in liquid nitrogen. Release of ph-IкB was measured in ME RIPA lysates by Enzyme-Linked Immunosorbent Assay (ELISA) following the manufacturer's instructions. The ELISA was purchased from Cell Signaling (PathScan, phIкB $\alpha$ (Ser32) Sandwich ELISA Kit \#7355).

\section{Gene Expression Analysis}

Total RNA was extracted from ME using the RNeasy Mini extraction kit (Qiagen, Hilden, Germany) followed by treatment with deoxyribonuclease I (Ambion, Austin, USA) and reverse transcribed to complementary DNA using the High Capacity cDNA Reverse Transcription Kit (Applied Biosystems, Darmstadt, Germany). Expression of messenger RNA (mRNA) was quantified in triplicate by a real-time reverse transcriptase polymerase chain reaction (RT-PCR). Gene expression data was normalized to the housekeeper gene GAPDH. For primer sequences, primer assays or TaqMan probes used see Table 2. Quantitative polymerase chain reaction was performed with SYBR Green PCR Master Mix (Applied Biosystems) or TaqMan Gene Expression Master Mix (Applied Biosystems).

\section{RNA-Seq Library Preparation, Sequencing}

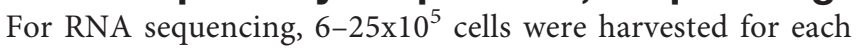
sample and lysed in TRIzol (Invitrogen). Total RNA was
TABLE 2 | Primer sequences, primer assays and Taqman probes used for quantitative RT-PCR.

\begin{tabular}{lll}
\hline Gene name & \multicolumn{2}{c}{ Primer sequences (Metabion) } \\
\cline { 2 - 3 } & \multicolumn{1}{c}{ forward } & \multicolumn{1}{c}{ reverse } \\
\hline EGR-1 & 5-GAGCGAACA & 5-GGCCAGTAT \\
ISG15 & ACCCTATGAGC-3 & AGGTGATGGGA-3 \\
& 5-CCCCAGCAT & 5-TGACTGTGA \\
USP18 & CTTCACCTTA-3 & GAGCAAGCAGC-3 \\
TLR3 & 5-GTGTCCGTG & 5-CTGCAGAAA \\
& ATCTGGTCCTT-3 & TACAACGTGCC-3 \\
Gene name & 5-GCCTGAATC & 5-AGCCCAGAT \\
IL-1 $\alpha$ & ACAATCGCGCACC-3 & TATGGGTGCAATCCCT-3 \\
IFN- $\beta$ & QuantiTect Primer Assay ID (Qiagen) \\
\hline Gene name & QT00113505 & \\
\hline IL-6 & QT00249662 & Taqman Probes Assay ID (Applied Biosystems) \\
IL-1 $\beta$ & Mm00446190 \\
GAPDH & Mm00434228 \\
\hline
\end{tabular}

extracted according to the manufacturer's protocol. The precipitated RNA was re-suspended in RNase-free water and RNA quantity and quality (RIN) were assessed via the RNA analysis screen tape assay on a 2200 TapeStation system (Agilent Technologies). Total RNA was converted into double-stranded cDNA libraries as a template for highthroughput sequencing using the TruSeq RNA Sample Preparation Kit v2 (Illumina). cDNA libraries were quantified with the KAPA Library Quantification Kit (Kapa Biosystems). After cluster generation on a cBot (Illumina), a 75 bp single read, rapid run was performed on a HiSeq1500 (Illumina).

\section{RNA-Seq Data Analysis}

After base calling and de-multiplexing using CASAVA version 1.8.2, data RNA-Seq libraries were subjected to initial quality control using FASTQC (http://www.bioinformatics.babraham. ac.uk/projects/fastqc, v0.11.7). Next, raw reads were pseudoaligned to the murine transcriptome ( $\mathrm{mm} 10$, GENCODE general assembly release vM16) using Kallisto with default settings (25). Based on the pseudo alignment estimated by Kallisto, transcript levels were quantified and counts were imported into R using tximport (26). Transcript information was summarized on gene-level. We imported the resulting dataset and performed the downstream analysis using the DESeq2 pipeline [v1.2(27)].

\section{Statistical Analysis}

Statistical analysis was performed using Graph Pad Prism Version 8.4.3 for Windows software (GraphPad Software, San Diego, CA). Data were analyzed by two-way ANOVA with Tukey post hoc test, one-way ANOVA with Bonferroni post hoc test or a student's t-test as indicated. The data are shown as the means \pm SEM. 


\section{RESULTS}

\section{TRIF Deficient Mice Are Protected From Postoperative lleus}

In a first set of experiments, we investigated the role of TRIF in a standardized POI model. Wt and $\mathrm{TRIF}^{-/-}$mice were subjected to a surgical IM procedure and small bowel ME specimens were analyzed for gene expression of different cytokines or $\mathrm{MPO}^{+}$ leukocyte infiltration 3 or $24 \mathrm{~h}$ after IM, respectively. After $3 \mathrm{~h}$, IL-6 ( $\mathrm{p} \leq 0.001)$, EGR-1 ( $\mathrm{p} \leq 0.01)$, IL- $1 \alpha(\mathrm{p} \leq 0.01)$, and IL-1 $\beta$ ( $\mathrm{p} \leq 0.001$ ) were increased (Figures 1A-D) in intestinally manipulated wt animals compared to naive controls (ctrl) and $\mathrm{TRIF}^{-/-}$mice. The latter showed a reduced expression of IL- 6 ( $\mathrm{p} \leq$ $0.01)$, EGR-1 ( $\leq 0.01)$, IL-1 $\alpha(\mathrm{p} \leq 0.05)$ and IL-1 $\beta(\mathrm{p} \leq 0.001)$. After $24 \mathrm{~h}, \mathrm{MPO}^{+}$cell counts were increased $(\mathrm{p} \leq 0.001)$ in wt and in $\mathrm{TRIF}^{-/-}$mice, but TRIF deficiency resulted in reduced infiltration ( $\mathrm{p} \leq 0.001$ ) compared to the wt IM group (Figure 1E). Correspondingly, the gastrointestinal transit (GIT) of wt mice was decreased $24 \mathrm{~h}$ after IM compared to ctrl ( $\mathrm{p} \leq 0.001)$ while intestinally manipulated $\mathrm{TRIF}^{-/-}$mice had an accelerated GIT ( $\mathrm{p} \leq 0.01)$ (Figure 1F). These data indicate that TRIF plays a crucial role in POI.

\section{TLR3 Deficient Mice Are Protected From Postoperative lleus}

TRIF is recruited after TLR3 or TLR4 ligation. As we previously discovered that TLR4 deficient mice were not protected from POI and that postoperative cytokine expression and leukocyte infiltration were also unaffected (7) in TLR4 deficient mice we focused our further investigations on TLR3 signaling. Again, in the intestinally manipulated wt animals IL-6 ( $\mathrm{p} \leq 0.01)$, EGR-1 ( $\mathrm{p} \leq 0.001)$, IL-1 $\alpha(\mathrm{p} \leq 0.001)$, and IL-1 $\beta$ ( $\mathrm{p} \leq 0.001)$ gene expression was increased after $3 \mathrm{~h}$ (Figures 2A-D). Intestinally manipulated $\mathrm{TLR}^{-/-}$mice showed a diminished production of $\mathrm{ph}-\mathrm{I} \kappa \mathrm{B}(\mathrm{p} \leq 0.05$; Supplementary Figure S1), which resulted in a reduced upregulation of EGR-1 ( $\mathrm{p} \leq 0.001)$, IL- $1 \alpha$ (p $\leq 0.05)$ and IL$1 \beta(\mathrm{p} \leq 0.01)$ while IL-6 was slightly increased $(\mathrm{p}=0.059)$. Infiltrating $\mathrm{MPO}^{+}$cells were reduced in $\mathrm{TLR}^{-/-}$mice $(\mathrm{p} \leq$ 0.001 ) compared to the wt IM group (Figure 2E) and the GIT was accelerated $(\mathrm{p} \leq 0.001)$ (Figure $2 \mathrm{~F})$. Together, these data demonstrate the involvement of a TLR3-TRIF signaling axis in postoperative ME inflammation in POI.

\section{A Type I IFN Response Does Not Contribute to Postoperative lleus}

TLR3 has been well elucidated to be involved in both, the production of proinflammatory cytokines and the induction of type I IFNs, with the latter particularly occurring after viral or bacterial infections. While our data show that the cytokine response is diminished in TLR3 deficient mice, it was unclear if a type I IFN response might also contribute to POI pathogenesis. Therefore, we first determined if wt mice develop a type I IFN signature upon IM. IFN- $\beta$ as well as the
IFN-stimulated genes (ISGs) ISG15 and USP18 were upregulated at different time points up to $12 \mathrm{~h}$ after IM while OAS1b was only slightly upregulated after $24 \mathrm{~h}$ (Figure 3A). In $\mathrm{TLR}^{-/-}$mice, this IM-mediated induction of IFN- $\beta$ ( $\left.\mathrm{p} \leq 0.01\right)$, ISG15 ( $\mathrm{p} \leq 0.01$ ) and USP18 ( $\mathrm{p} \leq 0.05)$ was decreased (Figure 3B). IFN- $\alpha 2$, another type I IFN, was also upregulated within the immediate phase (Figure 3C). As the upregulation of ISGs was less pronounced compared to the type I interferons itself, we aimed to confirm type I IFN production on the protein level. IFN- $\beta \mathrm{uuc}^{+/-}$mice were subjected either to IM, to an i.p. injection of polyI:C or were left untreated. While polyI:C treated mice demonstrated an IFN- $\beta$-promotor driven luciferase response at 3,6 , and $24 \mathrm{~h}$ after injection (Supplementary Figures S2A,B), intestinally manipulated mice as well as naive mice did not show any luciferase activity in vivo, demonstrating that IFN- $\beta$ protein is not produced during POI. In order not to overlook any effects of other type I IFNs we additionally subjected IFNAR $^{-/-}$mice, which are unable to respond to all type I IFNs, to IM. Again, we did not observe any difference in GIT reduction between IFNAR $^{-/-}$and wt mice, neither between the naive nor between the IM groups (Figure 3D), and numbers of infiltrating $\mathrm{MPO}^{+}$ leukocytes were comparably increased in $\mathrm{IFNAR}^{-/-}$and $\mathrm{wt}$ mice (Figure 3E). Furthermore, flow cytometry analysis of CD $45^{+}(p=0.15)$, Ly6G ${ }^{-} \mathrm{Ly}_{6} \mathrm{C}^{+}(\mathrm{p}=0.07), \mathrm{Ly}^{+} \mathrm{G}^{+} \mathrm{Ly}_{6} \mathrm{C}^{+}$ $(\mathrm{p}=0.34)$ and $\mathrm{F} 4 / 80^{+} \mathrm{Ly}_{6 \mathrm{G}}{ }^{-}(\mathrm{p}=0.77)$ cells in the postoperative ME did not reveal any differences between IFNAR $^{-/-}$and wt mice (Supplementary Figure S3). Collectively, our data demonstrate that type I IFNs do not contribute to POI's pathophysiology, indicating that the protective effect of TRIF or TLR3 deficiency is mediated by the reduced proinflammatory cytokine response.

\section{TLR3 Signals Via Resident Radio- Resistant Tissue Cells}

Next, we aimed to further characterize the relevant TLR3 signaling cell type in POI and performed a bone marrow (BM) transplantation experiment in which either wt mice or TLR3 ${ }^{-1-}$ underwent lethal irradiation followed by an injection of healthy bone marrow from TLR3 $^{-/-}$(wt x TLR3 ${ }^{-/-\mathrm{BM}}$ ) or wt mice (TLR3 $^{-1-} \mathrm{x}$ $\left.\mathrm{wt}^{\mathrm{BM}}\right)$, respectively. Irradiation control groups were wt mice that received wt bone marrow ( $\mathrm{wt} \times \mathrm{wt}^{\mathrm{BM}}$ ) and $\mathrm{TLR}^{-/-}$mice that received $\mathrm{TLR}^{-/-}$bone marrow $\left(\mathrm{TLR}^{-/-} \times \mathrm{TLR}^{-/-\mathrm{BM}}\right.$ ) (Figure 4A). If TLR3 signaling involves local resident cells, that should be predominantly radio-resistant cells, one would expect a reduced postoperative leukocyte infiltration in $\mathrm{TLR}^{-/-} \mathrm{x} \mathrm{wt}^{\mathrm{BM}}$. In turn, involvement of bone marrow-derived cells, which are known to be radio-sensitive and give rise to blood leukocytes that infiltrate the postoperative $\mathrm{ME}$, would rather become obvious by a reduced cell infiltration in wt $\mathrm{x}$ TLR3 $3^{-/-\mathrm{BM}}$ mice. Indeed, $\mathrm{TLR}^{-/-} \mathrm{x} \mathrm{wt}^{\mathrm{BM}}$ showed decreased numbers of infiltrating $\mathrm{MPO}^{+}$cells $(\mathrm{p} \leq 0.05)$ compared to wt $\mathrm{x}$ TLR3 $3^{-/-\mathrm{BM}} 24 \mathrm{~h}$ after IM (Figure 4B). In accordance, the GIT of TLR3 ${ }^{-/-} \mathrm{x} \mathrm{wt}^{\mathrm{BM}}$ was improved $(\mathrm{p} \leq 0.05)$ compared to wt $\mathrm{x} \mathrm{TLR}^{-/-\mathrm{BM}} 24 \mathrm{~h}$ after IM (Figure 4C). Furthermore, $\mathrm{MPO}^{+}$cells in $\mathrm{TLR}^{-/-} \mathrm{x} \mathrm{wt}^{\mathrm{BM}}$ 
A

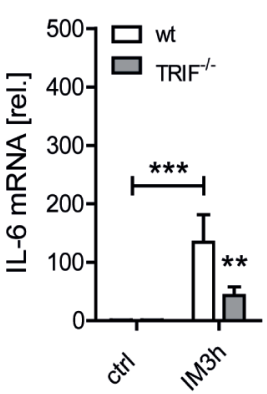

C

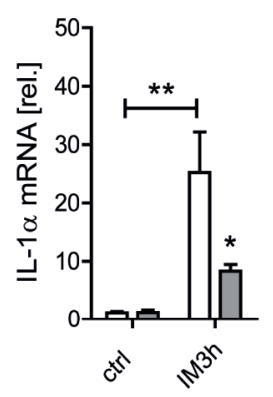

E

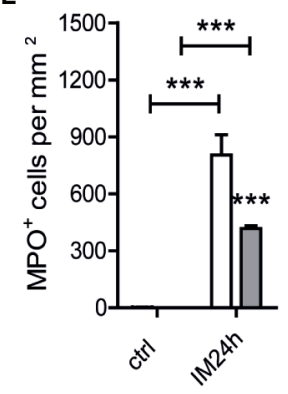

B

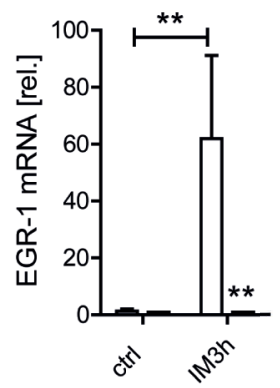

D

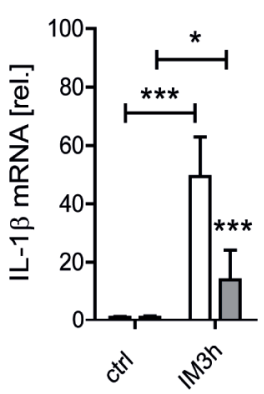

F

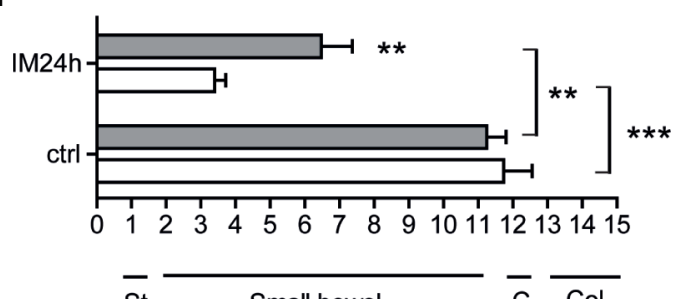
TRIF

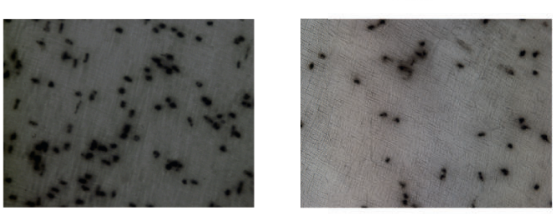

IM24h

FIGURE 1 | TIR-domain-containing adapter-inducing interferon- $\beta$ (TRIF) deficient mice are protected from postoperative ileus (POI). Wt and TRIF ${ }^{-/-}$mice underwent IM or were left untreated (ctrl). (A-D) Three hours after surgery (IM3h), IL-6, EGR-1, IL-1 $\alpha$, and IL-1 $\beta$ gene expression levels were analyzed within the muscularis externa (ME) and displayed as fold changes after normalization to ctrl. (E) MPO ${ }^{+}$leukocyte numbers were identified by Hanker-Yates reaction in mucosal-free muscularis whole mounts $24 \mathrm{~h}$ after surgery (IM24h). (F) Gastrointestinal (GI) transit time was determined by distribution of a fluorescent meal along the Gl tract within a defined time period. Data were calculated as geometric center of the fluorescence marker distribution. Geometric center (GC) values reciprocally correlate to the motility. St, stomach; $\mathrm{C}$, cecum; Col, colon. Experiments were performed two to four times reaching an overall size of $\mathrm{n}=$ 3-10 animals per group. Means + SEM were generated from the overall numbers of each group. Samples were analyzed by two-way analysis of variance with Tukey post hoc test and the results are displayed as means \pm SEM. ${ }^{*} p \leq 0.05,{ }^{* *} p \leq 0.01$, ${ }^{* \star *} p \leq 0.001$ versus the corresponding wt group or between indicated groups.

compared to wt $\mathrm{x} \mathrm{wt}^{\mathrm{BM}}$ were also significantly decreased ( $\mathrm{p} \leq$ 0.05 ) and accordingly, these mice showed an improved GIT ( $\mathrm{p} \leq$ 0.05). Notably, this improvement was comparable to the accelerated GIT of intestinally manipulated TLR3 $3^{-/-} \times \mathrm{TLR}^{-/-\mathrm{BM}}$ mice compared to the wt $\mathrm{x}$ wt ${ }^{\mathrm{BM}}$ group. Taken together, these data indicate that TLR3 signaling rather occurs in radio-resistant (mostly likely tissue resident) cells than in radio-sensitive (most likely infiltrating blood-derived) cells during POI. 
A

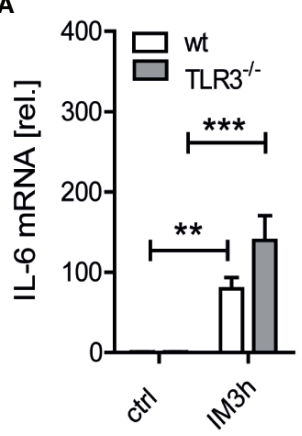

C

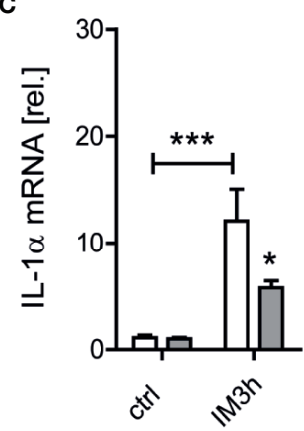

E

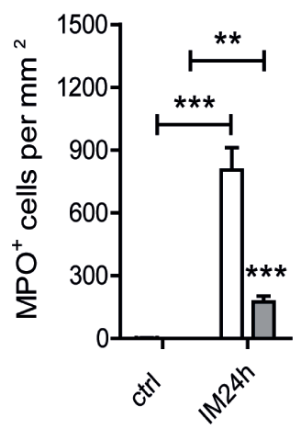

B

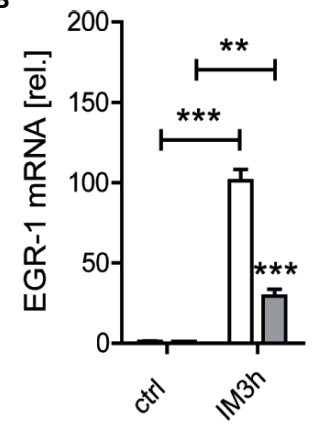

D

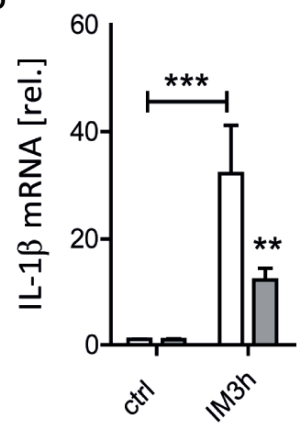

$\mathbf{F}$

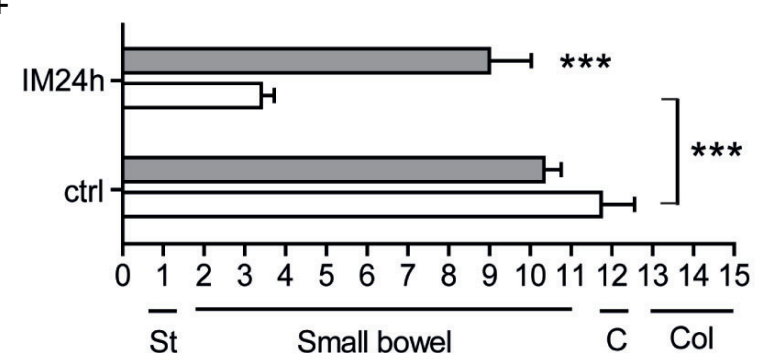

FIGURE 2 | Toll-like receptor 3 (TLR3) deficient mice are protected from postoperative ileus (POI). Wt and TLR3 $3^{-/-}$mice underwent IM or were left untreated (ctr). (A-D) Three hours after surgery (IM3h), IL-6, EGR-1, IL-1 $\alpha$ and IL-1 $\beta$ gene expression levels were analyzed within the muscularis externa (ME) and displayed as fold changes after normalization to ctrl. (E) MPO+ leukocyte numbers were identified by Hanker-Yates reaction in mucosal-free muscularis whole mounts $24 \mathrm{~h}$ after surgery (IM24h). (F) Gastrointestinal (GI) transit time was determined by distribution of a fluorescent meal along the Gl tract within a defined time period. Data were calculated as geometric center of the fluorescence marker distribution. Geometric center (GC) values reciprocally correlate to the motility. St, stomach; C, cecum; Col, colon. Experiments were performed two to four times reaching an overall size of $n=3-13$ animals per group. Means + SEM were generated from the overall numbers of each group. Samples were analyzed by two-way analysis of variance with Tukey post hoc test and the results are displayed as means \pm SEM. ${ }^{*} \mathrm{p} \leq 0.05$, ${ }^{* *} \mathrm{p} \leq 0.01,{ }^{* \star *} \mathrm{p} \leq 0.001$ versus the corresponding wt group or between indicated groups. 
A
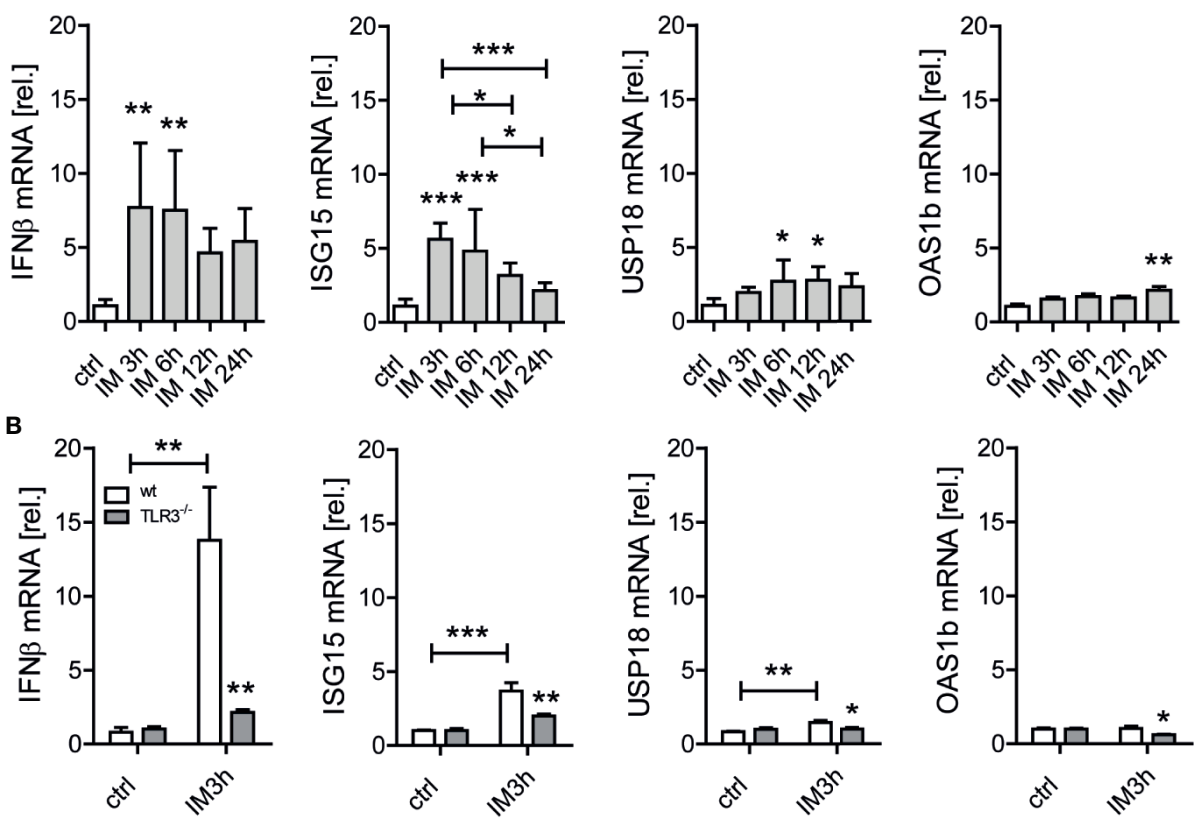

C
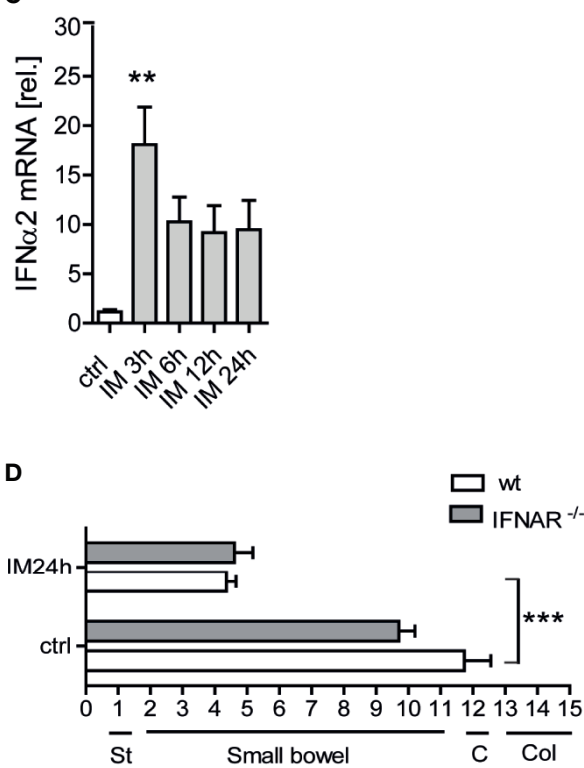

E

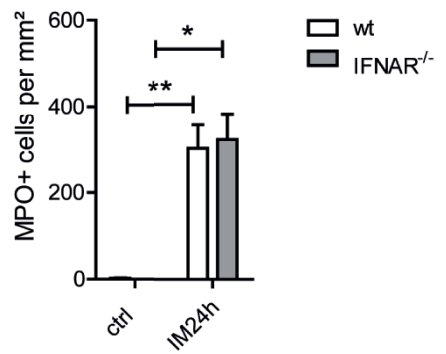

FIGURE 3 | A type-I IFN response does not contribute to postoperative ileus (POI). Wt and TLR3 ${ }^{-/}$mice underwent IM or were left untreated (ctrl).

(A, B) IFN- $\beta$ and interferon stimulated genes (ISG) ISG15, USP18, and OAS1b as well as (C) IFN $\alpha 2$ gene expression were analyzed at the indicated time points within the ME and displayed as fold changes after normalization to ctrl. $n=7$ for all groups. Samples were analyzed by one-way analysis of variance or two-way analysis of variance with Bonferroni or Tukey post hoc test, respectively, and the results are displayed as means $\pm \mathrm{SEM}$. ${ }^{*} \mathrm{p} \leq 0.05$, ${ }^{* *} \mathrm{p} \leq 0.01$, ${ }^{* * *} \mathrm{p} \leq 0.001$ versus indicated groups. (D-E) Wt and IFNAR ${ }^{-/-}$mice underwent intestinal manipulation (IM) or were left untreated (ctrl). (D) Gastrointestinal (GI) transit time was determined by distribution of a fluorescent meal along the Gl tract within a defined time period. Data were calculated as geometric center of the fluorescence marker distribution. Geometric center (GC) values reciprocally correlate to the motility. St, stomach; C, cecum; Col, colon. (E) MPO+ leukocyte numbers were identified by Hanker-Yates reaction in mucosal-free muscularis whole mounts $24 \mathrm{~h}$ after surgery (IM24h). St, stomach; C, cecum; Col, colon. Experiments were performed two to three times reaching an overall size of $n=7$ animals per group. Means + SEM were generated from the overall numbers of each group. Samples were analyzed by two-way analysis of variance with Tukey post hoc test and the results are displayed as means $\pm \mathrm{SEM} .{ }^{*} \mathrm{p} \leq 0.05,{ }^{* *} \mathrm{p} \leq 0.01,{ }^{* * *} \mathrm{p} \leq 0.001$ versus the corresponding wt group or between indicated groups. 
A
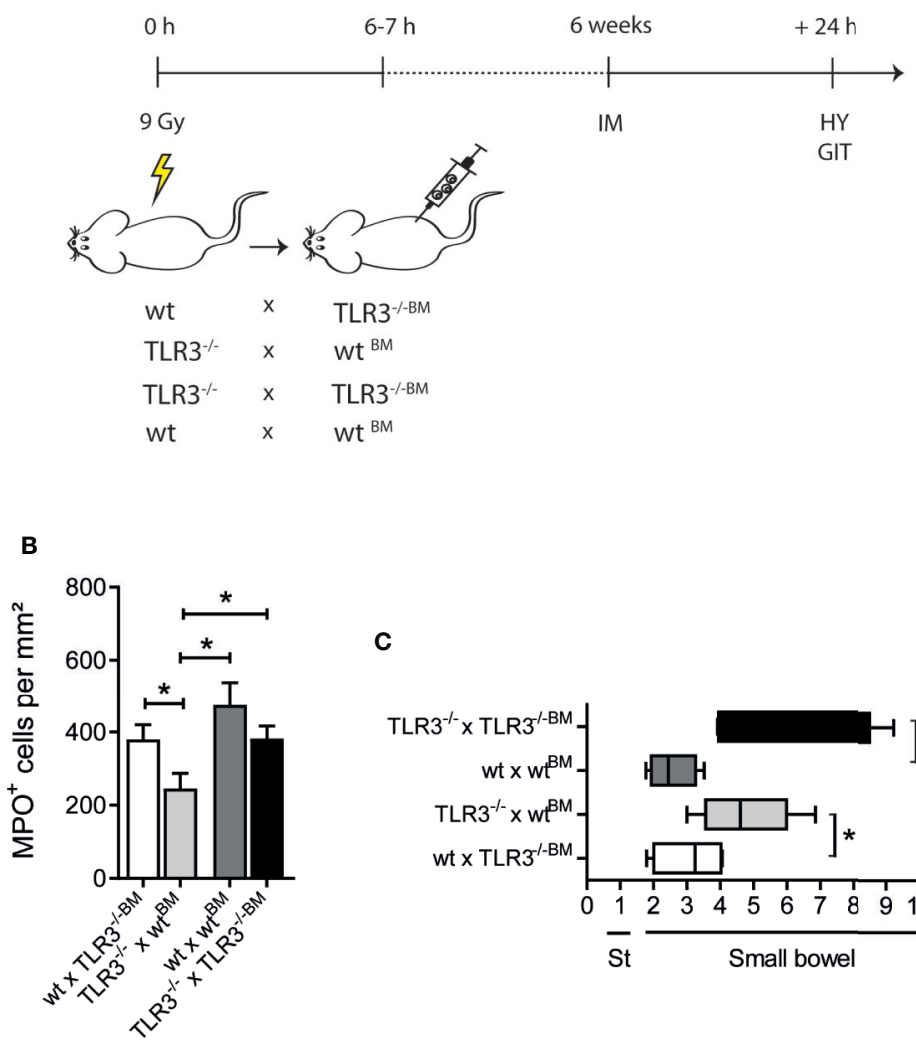

C

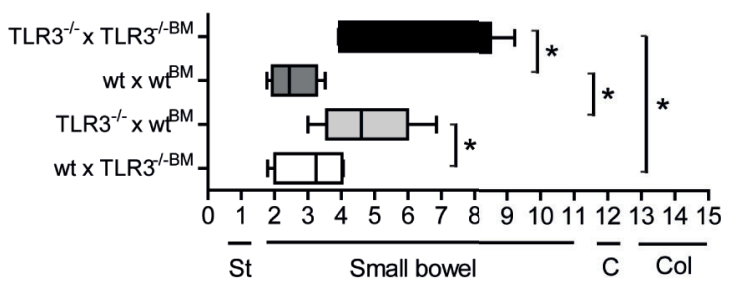

FIGURE 4 | Toll-like receptor 3 (TLR3) signals via resident radio-resistant tissue cells. (A) Lethally irradiated host mice were recovered 6-7 h after radiation with a

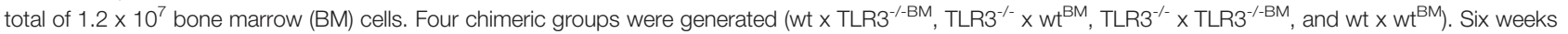
later, all four groups underwent intestinal manipulation (IM). (B) $\mathrm{MPO}^{+}$leukocyte numbers were identified by Hanker-Yates (HY) reaction in mucosal-free muscularis whole mounts $24 \mathrm{~h}$ after surgery (IM24h). TLR3 ${ }^{-/-}$that received wt bone marrow showed lower leukocyte infiltration compared to wt mice that received TLR3 ${ }^{-1-}$ bone marrow. (C) Gastrointestinal (Gl) transit time was determined by distribution of a fluorescent meal along the Gl tract within a defined time period. Data were calculated as geometric center of the fluorescence marker distribution. Geometric center (GC) values reciprocally correlate to the motility. St, stomach; C, cecum; $\mathrm{Col}$, colon. Experiments were performed two times reaching an overall size of $n=6$ animals per group. Means + SEM were generated from the overall numbers of each group. Samples were analyzed by two-way analysis of variance with Tukey post hoc test and the results are displayed as means \pm SEM. ${ }^{*} \mathrm{p} \leq 0.05$ versus indicated groups.

\section{Radio-Resistant MHCII ${ }^{\text {hi }}$ CX3CR1- Cells Express the Macrophage Marker IBA-1 and Reside Within a Special Anatomical Niche}

Although TLR3 can be expressed by a variety of cell types, it is mainly expressed on leukocytes. In the intestinal ME, a dense network of CX3CR $1^{+}$macrophages is known to express TLRs and their contribution to POI is common knowledge $(28,29)$. Early work demonstrated that depletion and inactivation of these cells ameliorates POI Considering our observation that TLR3 and TRIF demonstrated reduced immune mediator transcripts already in the early phase of POI, we expected that these resident macrophages, rather than the later infiltrating blood-derived monocytes, might be the relevant cell population of TLR3 signaling. However, in this case and in line with the bone marrow chimera experiments these cells should be - at least to a significant part - radio-resistant. To test this hypothesis we lethally irradiated belly-shielded and non-shielded CX3CR1 $1^{\mathrm{GFP} /+}$ chimeras and reconstituted them with $\mathrm{BM}$ of LysM $^{\text {cre+ }}$;ROSA26 ${ }^{\text {LSL-eYFP }}$ mice (Figure 5A). Replacement of CX3CR $1^{\mathrm{GFP} /+}$ cells by bone marrow derived LysM-expressing $\mathrm{YFP}^{+}$leukocytes would indicate if the resident CX3CR $1^{+}$ macrophages are radio-resistant or to which extent they might become replaced by bone-marrow derived progenitors. Six weeks after BM transplantation recipients were analyzed for the presence of $\mathrm{GFP}^{+}$and $\mathrm{YFP}^{+}$cells in the ME (for gating strategies see Supplementary Figure S4). After irradiation and BM transplantation we detected an overall decrease in $\mathrm{MHCII}^{\mathrm{hi}} \mathrm{GFP}^{+}$ cells in non-shielded versus shielded mice (shielded: $50.2 \%$, nonshielded: $8.8 \%$ ) and an influx of $\mathrm{YFP}^{+}$cells in irradiated nonshielded animals (shielded: 0\%; non-shielded: 30.0\%) (Figure 5B). While MHCII ${ }^{\text {hi }}$ GFP/CX3CR ${ }^{+}$cells were reduced upon irradiation, no reduction among $\mathrm{MHCII}^{\text {hi }} \mathrm{GFP} / \mathrm{CX} 3 \mathrm{CR} 1^{-}$cells was observed (Figure 5C). The overall number of $\mathrm{CD} 45^{+}$ cells was not altered (Supplementary Figure S5) and 
A

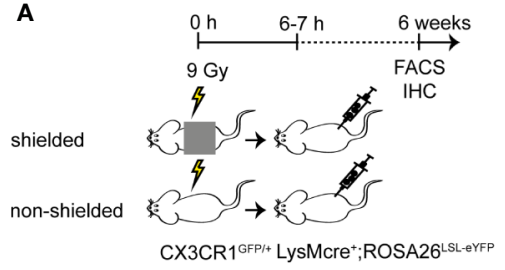

B<smiles>[13CH3][13CH3]</smiles>

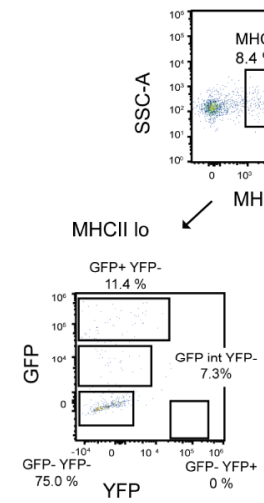

D

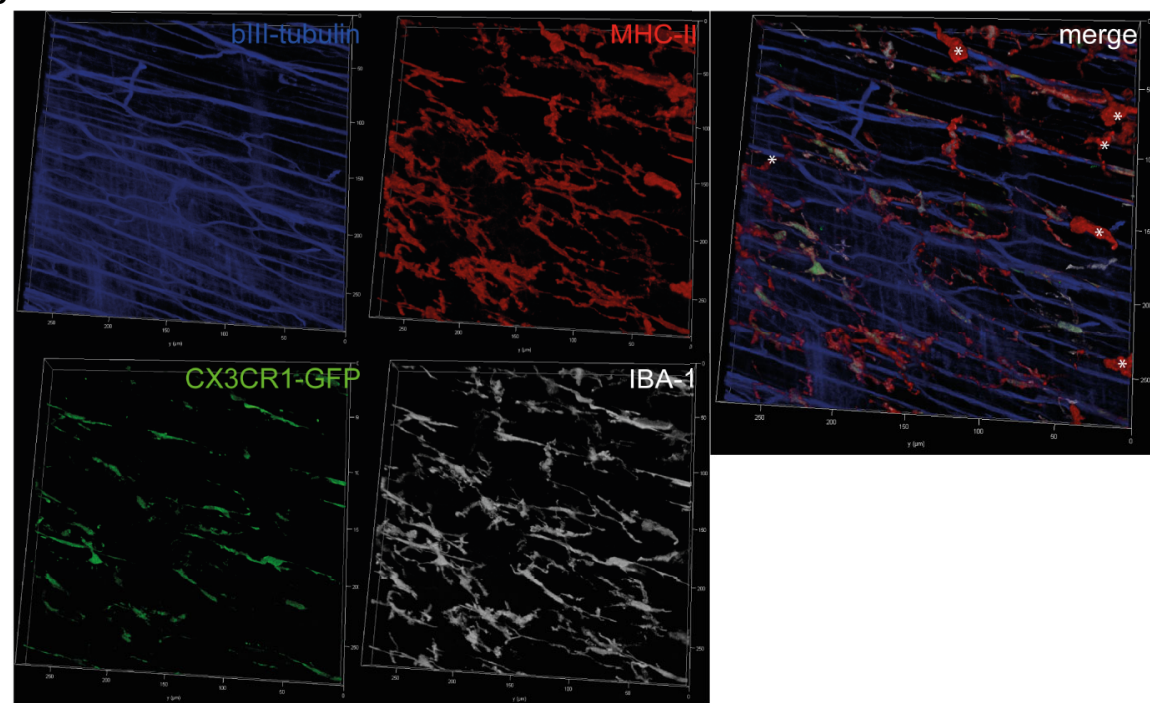

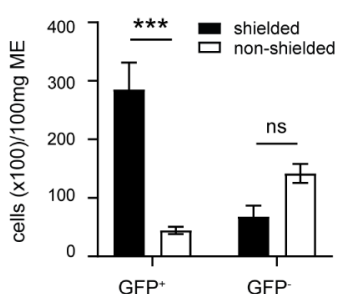

3

non-shielded

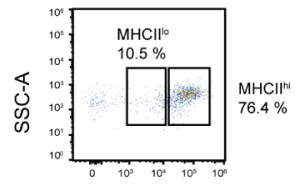

MHCII lo $\searrow \quad$ MHCll hi

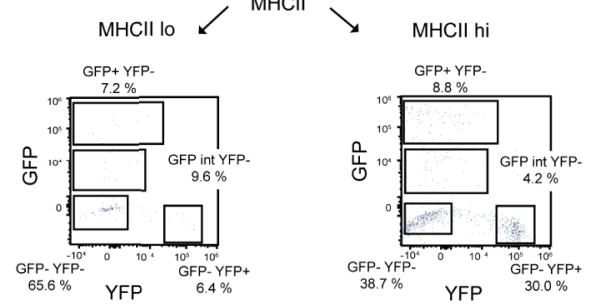

GFP + YFP-
$50.2 \%$

员
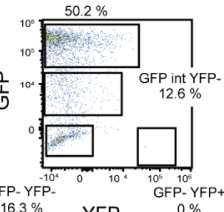

$16.3 \%$ YFP

GFP-YFP-
$65.6 \%$

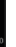

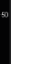

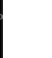

FIGURE 5 | Radio-resistant MHCII ${ }^{\text {hi }} \mathrm{CX} 3 \mathrm{CR} 1^{-}$cells express the macrophage marker IBA-1 and reside within a special anatomical niche. (A-C) Lethally irradiated shielded and non-shielded CX3CR1 ${ }^{\mathrm{GFP} /+}$ were recovered 6-7 h after radiation with a total of $1.2 \times 10^{7}$ bone marrow (BM) cells of LysM ${ }^{\text {cre }+}$; ROSA26 ${ }^{\mathrm{LSL}-e \mathrm{YFP}}$ donor mice. Six weeks later, fluorescence activated cell sorting (FACS) analysis and whole mount immunohistochemistry (IHC) was performed. (A) Scheme of the experimental setup. (B) Representative FACS plots of the expression of GFP (CX3CR1)/YFP (LysM) on living CD45 ${ }^{+} \mathrm{MHCl}^{\text {hi }} / \mathrm{MHCl \| ^{ \textrm {l } }}$ gated cells isolated from the ME

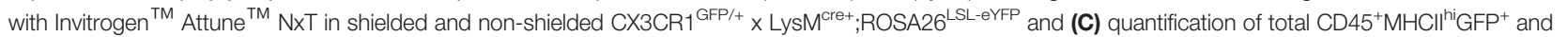

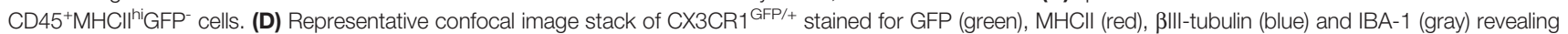
the existence of a $\mathrm{MHCl}{ }^{\mathrm{hi}} \mathrm{IBA}-1^{+} \mathrm{CX} 3 \mathrm{CR} 1^{-}$cell population $\left(^{*}\right)$ located in a different layer than the $\mathrm{MHCl}{ }^{\mathrm{hi}} \mathrm{IBA}-1^{+} \mathrm{CX} 3 \mathrm{CR} 1^{+}$cells. Experiments were performed three times reaching an overall size of $n=3$ animals per group. Means + SEM were generated from the overall numbers of each group. Samples were analyzed by student's t-test and the results are displayed as means \pm SEM. ${ }^{* \star *} \mathrm{p} \leq 0.001$. For images on the localization, please refer to Supplementary Figure S7.

additionally immunohistochemical quantification of ileal whole mount specimen in shielded and non-shielded irradiated CX3CR $1^{\mathrm{GFP} /+}$ mice upon $\mathrm{LysM}^{\mathrm{cre+}}$;ROSA26 $6^{\mathrm{LSL}-\mathrm{eYFP}} \mathrm{BM}$ transplantation confirmed that also the overall number of
$\mathrm{MHCII}^{+}$cells was not altered. Notably, the MHCII staining included both, $\mathrm{GFP}^{+}$and $\mathrm{YFP}^{+}$cells (Supplementary Figure S6), indicating that the loss in $\mathrm{MHCII}{ }^{\text {hi }} \mathrm{CX} 3 \mathrm{CR} 1^{+}$cells, detected by flow cytometry, might be compensated by MHCII ${ }^{\text {hi }}$ leukocytes 
that were or became $\mathrm{CX} 3 \mathrm{CR} 1^{-}$. As all $\mathrm{MHCII}^{+}$cells appear in their typical stellate/bipolar morphology, we assume that the $\mathrm{YFP}^{+} \mathrm{BM}$ derived cells indeed replaced $\mathrm{CX} 3 \mathrm{CR} 1^{+}$cells after irradiation.

We next aimed to precisely locate the $\mathrm{MHCII}^{\mathrm{hi}} \mathrm{CX} 3 \mathrm{CR} \mathrm{1}^{-}$ population within the $\mathrm{ME}$ of naive $\mathrm{CX} 3 \mathrm{CR} 1^{\mathrm{GFP} /+}$ mice. Confocal immunohistochemistry with antibodies directed against GFP, expressed under the control of the CX3CR1 promotor and against MHCII indeed identified three different $\mathrm{MHCII}^{+}$ immunocyte populations (Figure 5D). Two $\mathrm{CX}_{3} \mathrm{CR} 1^{+}$cell populations in close proximity to beta-III tubulin ${ }^{+}$enteric neurons of which one presented in a bipolar and the other one in a stellate-shaped morphology. These cells have already been characterized as resident macrophages of the serosal and myenteric plexus, respectively. The third $\mathrm{MHCII}^{+} \mathrm{CX} 3 \mathrm{CR} 1^{-}$ population was also stellate-shaped but located underneath both $\mathrm{CX} 3 \mathrm{CR} 1^{+}$populations. Notably, the CX3CR1- population was also located in close proximity to beta-III tubulin ${ }^{+}$enteric neurons. A $3 \mathrm{D}$ projection of the confocal images indeed confirmed the distinct anatomical niche distant to the $\mathrm{CX} 3 \mathrm{CR} 1^{+}$cell layers. This layer separation is shown in Supplementary Figure S7 and we conclude that $\mathrm{MCHII}^{+} \mathrm{CX} 3 \mathrm{CR}^{-}$cells lie in the deep myenteric plexus of the circular muscle layer. Importantly, a simultaneous IBA-1 immunostaining revealed that all $\mathrm{MHCII}^{+}$cells, including the CX3CR1- population, were highly IBA-1 positive (Figure 5D; Supplementary Figure S7), indicating that these cells are also resident macrophages. Additional flow cytometry analysis also demonstrated that the vast amount of the CX3CR1- was CD11b positive. Only a very small amount of these cells expressed CD11c and the prototypical DC marker CD103 (Supplementary Figure S8). Taken together, these data demonstrate that $\mathrm{MHCII}{ }^{\mathrm{hi}} \mathrm{CX} 3 \mathrm{CR} 1^{+}$resident $\mathrm{ME}$ macrophages are radio-sensitive while a $\mathrm{MHCII}^{\text {hi }} \mathrm{CX} 3 \mathrm{CR}^{-}$cell population presented with a radio-resistant phenotype. The latter are located in a distinct anatomical niche, the deep myenteric plexus, and express the common resident macrophage marker IBA-1.

\section{MHCII ${ }^{\text {hi }}$ CX3CR1' Cells Have a Unique Toll- Like Receptor Gene Expression Pattern}

As our bone-marrow chimera experiment revealed a particular role for TLR3 deficiency in radio-resistant cells, we hypothesized that the CX3CR1- cells might be responsible for the TLR3triggered cytokine response in POI. Following this hypothesis, we sorted $\mathrm{MHCII}{ }^{\text {hi }} \mathrm{CX} 3 \mathrm{CR} 1^{-}$and $\mathrm{MHCII}{ }^{\text {hi }} \mathrm{CX} 3 \mathrm{CR} 1^{+}$cells from the $\mathrm{ME}$ of naive $\mathrm{CX} 3 \mathrm{CR} 1^{\mathrm{GFP} /+}$ mice and compared their transcriptome by RNA sequencing (bulk RNA-seq). Principal component analysis (PCA) and hierarchical clustering of samples confirm a segregation of $\mathrm{CX} 3 \mathrm{CR} 1^{+}$and CX3CR1 populations according to their gene expression profiles. While CX3CR $1^{+}$cells clustered very closely, we observed some segregation in the $\mathrm{CX} \mathrm{CR} 1^{-}$cell population (Figure 6A) which indicates a certain heterogeneity. While the list of most differentially expressed genes also contained DC marker genes, we analyzed the MHCII ${ }^{\text {hi }} \mathrm{CX} 3 \mathrm{CR} 1^{-}$cells by flow cytometry for CD103, CD11b and CD11c expression, however, only a very small amount of cells expressed CD11c and CD103 while most cells were only positive for CD11b, confirming their myeloid origin (Supplementary Figure S8). These data indicate a very low and probably negligible contamination of the CX3CR1 macrophage population by a distinct DC fraction.

A total of 4,265 genes $(|\log F C| \geq \log (2) ; \leq 0.05$ adjusted pvalue) were differentially expressed between MHCII ${ }^{\text {hi }}$ CX3CR $1^{+}$ and $\mathrm{MHCII}^{\text {hi }} \mathrm{CX} 3 \mathrm{CR} 1^{-}$cells (Figure 6B, Supplementary Figure S9A). A list of the top 25 up- and downregulated genes is shown in Supplementary Figure S9B. Notably, although CX3CR1 ${ }^{-}$cells expressed lower CSF1R levels than CX3CR $1^{+}$cells they showed higher levels of Ear2, Fn1, and Lys1, which are characteristic markers of the monocyte-macrophage lineage. Next, we performed functional annotation of differentially expressed genes by gene set enrichment analysis. This shows that genes upregulated in $\mathrm{CX} 3 \mathrm{CR} 1^{-}$cells are associated with gene ontology terms including chemotaxis, ERK-signaling and cell-cell adhesion (Figure 6D). Genes that are downregulated in CX3CR1 ${ }^{-}$compared to $\mathrm{CX} 3 \mathrm{CR} 1^{+}$show significant enrichment for gene ontology terms including cell migration, defense response and IL-6 production (Figure 6C). Genes listed under the GO term positive regulation of cell migration where also differentially expressed. Interestingly, we found a unique TLR expression pattern, with TLR 3 and TLR 11 being predominantly expressed on CX3CR1 ${ }^{-}$cells while all the other TLRs were mainly expressed on $\mathrm{CX} 3 \mathrm{CR} 1^{+}$cells (Figure 6E).

\section{TLR3 Signaling in MHCII ${ }^{\text {hi }}$ CX3CR1' Cells Drives Cytokine Expression During POI}

In a final experiment, we aimed to investigate whether the early cytokine increase during POI indeed depends on TLR3 signaling in the $\mathrm{MHCII}^{\text {hi }} \mathrm{CX} 3 \mathrm{CR} 1^{-}$cells. Unfortunately, neither TLR3floxed mice nor cell-specific markers for the CX3CR1 population, which might be used to drive Cre expression to achieve a cell-type specific TLR3 depletion, did exist. Therefore we decided to sort TLR-deficient CX3CR $1^{+}$and $\mathrm{CX} 3 \mathrm{CR} 1^{-}$cells from $\mathrm{CX} 3 \mathrm{CR} 1^{\mathrm{GFP} /+} \mathrm{xTLR}^{-/-}$mice $3 \mathrm{~h}$ after IM and from naive controls to analyze gene expression of proinflammatory cytokines known to be involved in POI. Control cells were sorted from CX3CR $1^{\mathrm{GFP} /+} \mathrm{xTLR}^{+/+}$littermates. Notably, as we were strongly limited in the amount of viable cells after sorting we were not able to perform more comprehensive transcriptome analyses, particularly not in the $\mathrm{MHCII}^{\mathrm{hi}} \mathrm{CX} 3 \mathrm{CR} 1^{-}$population. None of the tested genes were upregulated after IM in the $\mathrm{CX} 3 \mathrm{CR} 1^{+}$population in TLR3 competent mice (Figure 7A), while all of them were induced in CX3CR1 ${ }^{-}$cells (IL-6, $\mathrm{p} \leq 0.01$; IL- $1 \alpha, \mathrm{p} \leq 0.001$; IL-1 $\beta, \mathrm{p}=0.08$ ) (Figure 7B). Unexpectedly, we observed an upregulation in IL-6 ( $\mathrm{p} \leq 0.01)$, IL- $1 \alpha(\mathrm{p} \leq 0.05)$ and IL- $1 \beta(\mathrm{p} \leq 0.05)$ in the $\mathrm{TLR}^{-/-} \mathrm{MHCII}^{\mathrm{hi}} \mathrm{CX} 3 \mathrm{CR} 1^{+}$population after IM, which was not detected in $\mathrm{MHCII}^{+} \mathrm{CX} 3 \mathrm{CR} 1^{-}$cells. In contrast, in the latter TLR3 deficiency resulted in a strong reduction in postoperative IL-6 ( $\mathrm{p} \leq 0.001)$, IL- $1 \alpha(\mathrm{p} \leq 0.001)$ and IL-1 $\beta$ ( $\mathrm{p} \leq 0.05)$ compared to $\mathrm{TLR}^{+/+} \mathrm{MHCII}^{\mathrm{hi}} \mathrm{CX} 3 \mathrm{CR} 1^{-}$ cells and levels did not differ from controls. These data indicate a specific role of TLR3 signaling in CX3CR1- cells in the early cytokine expression during POI. Although TLR3 is much lower expressed in $\mathrm{CX}_{3 \mathrm{CR}} 1^{+}$cells $(\log 2 \mathrm{FC}=1.2178578$; 

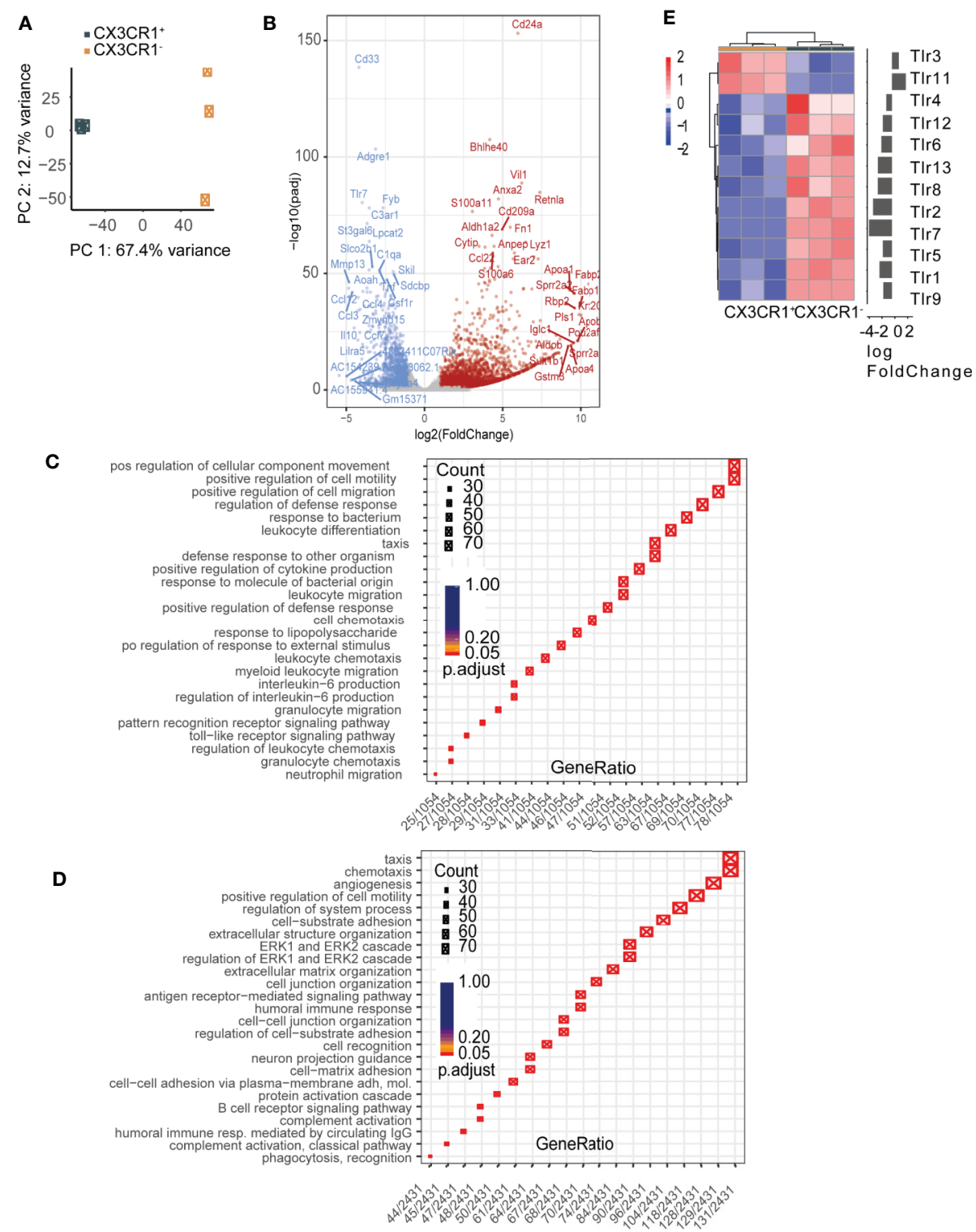

FIGURE 6 | Radio-resistant MHCI ${ }^{\text {hi } C X 3 C R} 1^{-}$cells express toll-like receptor 3 (TLR3). MHCII ${ }^{\text {hi }} \mathrm{CX} 3 \mathrm{CR} 1^{+}$and $\mathrm{MHCII}{ }^{\mathrm{hi}} \mathrm{CX} 3 \mathrm{CR} 1^{-}$cell populations were flow cytometry sorted from the muscularis externa (ME) of naive CX3CR1 $1^{\mathrm{GFP} /+}$ mice and underwent bulk RNA-seq. (A) Principal component analysis (PCA) and hierarchical clustering of samples confirming a segregation of $\mathrm{CX} 3 \mathrm{CR} 1^{+}$and $\mathrm{CX} 3 \mathrm{CR} 1^{-}$populations according to their gene expression profiles. (B) Volcano plot showing significantly (adj. p-value < 0.05) differentially expressed genes as upregulated (FoldChange $>1$, red) or downregulated (FoldChange $<1$, blue) genes. Gray genes do not pass differentially expressed thresholds. Top 15 most highly significant genes are labeled for up and downregulated genes. (C, D) Visual representation of GO terms associated with enriched genes versus gene ratio showing genes downregulated $(C)$ and upregulated $D$ in $C X 3 C R 1^{-}$cells compared to $C X 3 C R 1^{+}$cells. (E) Heatmap of TLR genes showing a unique expression pattern of TLR, with TLR3 and TLR11 being predominantly expressed on CX3CR1 ${ }^{-}$cells. $n=3$ (ME of six mice per group was pooled).

non- $\log 2 \mathrm{FC}=2.326011 ; \mathrm{p}$-value $=9.919200 \mathrm{e}-07)$, it seems to fulfill a different, rather inhibitory role, in the postoperative cytokine production.

In conclusion, our results show that IM triggers a TLR3 dependent proinflammatory cytokine expression during the onset phase of POI in MHCII ${ }^{\text {hi }} \mathrm{CX} 3 \mathrm{CR} 1^{-}$cells. Deficiency in TLR3 or downstream acting factor TRIF protects mice from POI. The MHCII ${ }^{\text {hi }}$ CX3CR $1^{-}$cells express IBA-1, a common resident macrophage marker, and reside in a specialized anatomical niche, the deep myenteric plexus (for a schematic illustration see Figure 7C).

\section{DISCUSSION}

In the present study, we demonstrate that the TRIF-TLR3 pathway plays a prominent role in POI by triggering the postoperative 
A

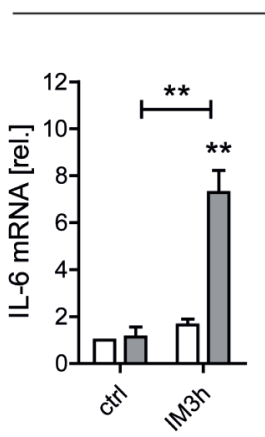

$\mathrm{MHCII}^{\mathrm{hi}}$

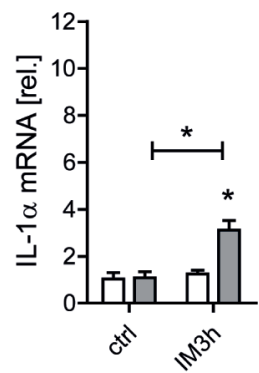

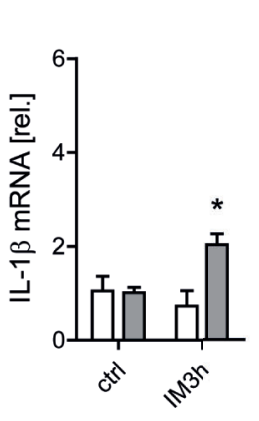

$\square \mathrm{TLR}^{+/+}$

B

$\mathrm{MHClI}^{\text {hi }}$
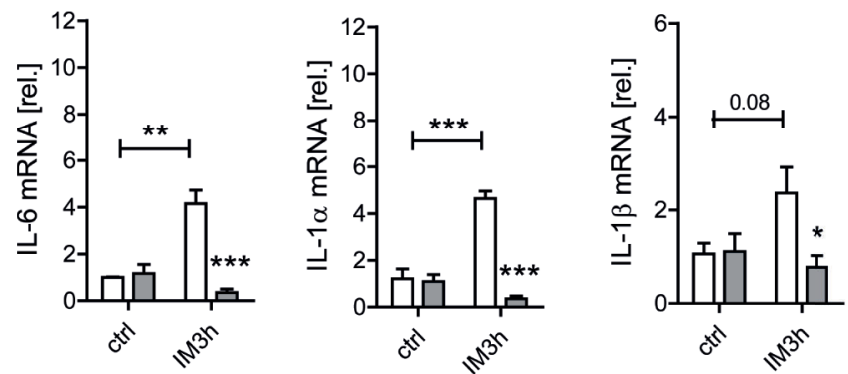

C

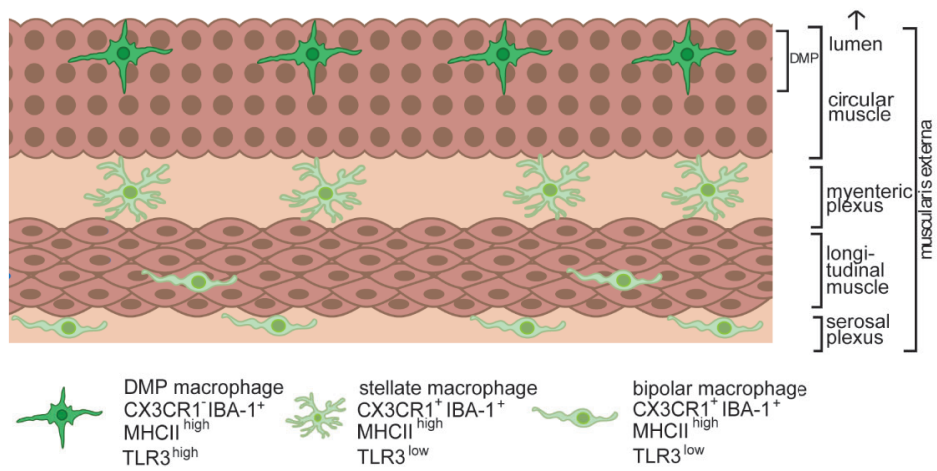

FIGURE 7 | Toll-like receptor 3 (TLR3) signaling in $\mathrm{MHCII}^{\text {hi }} \mathrm{CX} 3 \mathrm{CR} 1^{-}$cells drives cytokine expression during POI. Wt and TLR3 ${ }^{-/-}$mice underwent IM or were left

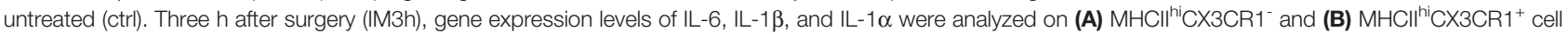
populations that had been sorted beforehand from the ME samples via fluorescence activated cell sorting (FACS) and displayed as fold changes after normalization to ctrl. $\mathrm{n}=3$ (each replicate was pooled from six mice). Samples were analyzed by two-way analysis of variance with Tukey post hoc test and student's t-test, respectively, and the results are displayed as means \pm SEM. Experiments were performed three times reaching an overall size of $n=3$ animals per group. Means + SEM were generated from the overall numbers of each group. ${ }^{*} \mathrm{p} \leq 0.05,{ }^{* *} \mathrm{p} \leq 0.01,{ }^{* \star \star} \mathrm{p} \leq 0.001$ versus the corresponding TLR3 ${ }^{+/+}$group or indicated groups. (C) Schematic drawing of the intestinal muscularis externa (ME) illustrating the location of bipolar or stellate MHCII ${ }^{\text {hi }} \mathrm{CX} 3 \mathrm{CR} 1^{+}$macrophages and MHCII ${ }^{\text {hi }} \mathrm{CX} 3 \mathrm{CR} 1$ macrophages. The latter reside within a distinct anatomical niche, the deep myenteric plexus (DMP), and express higher TLR3 levels while the MHCIl ${ }^{\text {i }} \mathrm{CX} 3 \mathrm{CR} 1^{+}$cells are located within the myenteric and serosal plexus and show low TLR3 expression. Intestinal manipulation (IM) triggers a proinflammatory cytokine expression during the onset phase of postoperative ileus (POI) mainly in MHCII ${ }^{\text {hi }}$ X $3 \mathrm{CR} 1^{-1}$ macrophages and this mechanism depends on TLR3 signaling.

cytokine response within the ME. Additionally, we also uncovered a subset of radio-resistant $\mathrm{CD} 45^{+} \mathrm{MHCII}{ }^{\text {hi }} \mathrm{CX} 3 \mathrm{CR} 1^{-}$macrophages to be responsible for this TLR3-mediated cytokine production.

Our results underline that POI is driven by a cytokine response which has been previously shown to play a crucial role in POI development $(30,31)$, including IL- $1 \alpha$, IL- $1 \beta(7,32)$, IL-6 (33), and Egr-1 (34). While IL-1 and Egr-1 were less induced in the postoperative ME of both, $\mathrm{TRIF}^{-/-}$and TLR3 ${ }^{-/-}$mice, IL-6 was only reduced in $\mathrm{TRIF}^{-/-}$but not in $\mathrm{TLR}^{-/-}$mice after IM. Therefore, the production of IL- 6 mRNA seems to be at least in 
some cells independent of TLR3 signaling. Indeed, we observed a reduction of IL-6 mRNA also in TLR4 ${ }^{-/-}$(7) indicating a certain involvement of TLR4 in IL-6 production with TLR4 also acting as an upstream receptor in the TRIF pathway. Notably, TLR $4^{-/-}$ mice did not show any improvement of POI. Although we can only speculate why $\mathrm{TLR}^{-/-}$mice are not protected from POI, a lack of TLR4 ligands seems to be unlikely due to the fact that bacteria can translocate into the ME upon IM (11). A counterbalance of the MyD88 pathway toward the TRIF pathway or intrinsic inhibitory effects of TRIF as described for TF5 - a TRIF-derived peptide - that inhibits TLR4 in a mouse model of LPS-induced inflammation (35) might be a possible explanation for this observation.

Alongside the cytokine release, we also observed an upregulation of a transcriptional type I IFN signature that was reduced in $\mathrm{TLR}^{-/-}$mice. In a series of experiments, we proved that this transcriptional type I IFN signature finally did not result in IFN- $\beta$ production and does not play a role in POI. The discrepancy between the transcriptional type I response and the lack of protein production might simply be explained by DNA contaminations in the mRNA preparations, as type I IFN genes lack introns (20) and RT-PCR cannot distinguish between genomic DNA or cDNA templates. Furthermore, type I IFNs and ISGs show protective but also harmful effects (36) and thus type I IFN response is tightly controlled at signaling, transcriptional and translational levels. To this end, IFN response control mechanisms such as the expression of specific microRNA are able to negatively regulate IFN-induced signaling through a Stat3 pathway (37) and USP18 and ISG15 were described to supress type I IFN-mediated responses by negatively regulating JAK/STAT (38). Both pathways are activated during POI (23). Although we solely analyzed protein expression of IFN- $\beta$ but not from ISGs or other type I interferons, we interpret the discrepancy in the elevated transcriptional type I IFN signature and the missing protein production as a protective mechanism to prevent an excessive immune response. The absence of any alteration in the postoperative immune cell infiltration and functional response during POI in $\mathrm{IFNAR}^{-/-}$mice, which lack any type I interferon response, supports this conclusion.

TLR expression along intestinal epithelium is well described, and recently it was shown that the presence of TLRs differs along the gastrointestinal tract (GI tract) (39). However, less is known about the cellular site of TLR3 expression in the ME and so far - in the GI tract-it has mostly been studied by immunohistochemistry and any knowledge about the role of TLR3 signaling and possible contributions to immune responses during POI are missing. Our data indicate that radio-resistant rather than radio-sensitive cells contribute to TLR3 signaling during POI. Alongside multiple immunocytes and epithelial cells of the mucosa, enteric neurons and glial cells express TLR3 (40) and as structural cells these cells might be radio-resistant. Notably, especially enteric glial cells - as nonclassical immunocytes - are also involved in POI's pathogenesis and the underlying mechanism involves the release of IL-6 and MCP-1 via an MyD88 and IL1R1-mediated pathway (7). In contrast, resident muscularis macrophages are well known to induce and to orchestrate the inflammatory process in the postoperative ME (4) and were already described to express TLRs such as TLR2 and TLR4 (41). Furthermore, they are selfmaintaining and only a minority undergoes replacement by bone marrow derived cells in naive mice (10). Therefore, we speculated that these resident macrophages might be responsible for TLR3/TRIF-mediated effects in POI and investigated whether these cells are radio-resistant. By use of CX3CR1 $1^{\mathrm{GFP} /+}$ mice, which express GFP in resident macrophages (8), we confirmed the previously described regular distribution of resident $\mathrm{ME}$ macrophages in the small bowel ME (9). Surprisingly, by co-labeling of MHCII, another highly expressed marker of murine and human $\mathrm{ME}$ macrophages (42), we not only identified $\mathrm{MHCII}^{+} \mathrm{CX} 3 \mathrm{CR} 1^{+}$ macrophages but also a population of $\mathrm{MHCII}^{+} \mathrm{CX} 3 \mathrm{CR} 1^{-}$cells. Like the CX3CR $1^{+}$macrophages, these cells also expressed IBA1, a well-known marker for resident microglia and macrophages, which also stains resident macrophages in the ME (43). 3D reconstructions of confocal images revealed that these cells lay in close proximity to beta-III tubulin ${ }^{+}$enteric nerves in a layer underneath the $\mathrm{CX} 3 \mathrm{CR} 1^{+}$cells (closer to the gut lumen), which are mainly found in the myenteric and serosal plexus (9). From these findings, we conclude that the MHCII ${ }^{\text {hi }}$ CX3CR1 ${ }^{-}$cells are a distinct population of resident macrophages localized in the deep myenteric plexus. Notably, a lack of $\mathrm{CX} 3 \mathrm{CR} 1^{+}$macrophages within the deep myenteric plexus has also just recently been observed by others (10). Additional evidence about a distinct macrophage subpopulation in the deep myenteric plexus comes from the Mikkelsen group, which already identified a specialized IBA- $1^{+}$CD $169^{-}$population in the deep myenteric plexus (44). Interestingly, our RNA-seq data also revealed strongly downregulated CD169 levels in the CX3CR1' population.

With regard to the radio-sensitivity of both resident macrophage populations we found a reduction of $\mathrm{CX} 3 \mathrm{CR} 1^{+}$ cells in the ME with a simultaneous increase of $\mathrm{YFP}^{+}$bonemarrow derived cells in irradiated $\mathrm{CX} 3 \mathrm{CR} 1^{\mathrm{GFP} /+}$ mice. As not all $\mathrm{MHCII}^{\mathrm{hi}} \mathrm{CX} 3 \mathrm{CR} 1^{+}$cells were replaced by $\mathrm{YFP}^{+}$cells, this population might be sensible in terms of radio-sensitivity or may even consist of different, so far non-distinguishable subtypes of macrophages. An alteration of the selfmaintenance of $\mathrm{CX} 3 \mathrm{CR} 1^{+} \mathrm{ME}$ macrophages and bone-marrow replacement was also recently shown in another bone-marrow transplantation study wherein the $\mathrm{CX} 3 \mathrm{CR} 1^{+}$resident cells were depleted by a diphtheria-toxin driven genetic approach (10). Although this study did not investigate if $\mathrm{CX} 3 \mathrm{CR} 1^{+}$cells of the $\mathrm{ME}$ are radio-resistant, it shows that these cells in general can be replenished by bone-marrow cells after genetic depletion. This is in line with our findings which identified LysM-YFP ${ }^{+}$bonemarrow derived cells as the source replenishing CX3CR $1^{+}$ resident cells after irradiation. Notably, six weeks after irradiation, all $\mathrm{MHC}^{+}$cells displayed microscopically a prototypical bipolar or stellate cell morphology, indicating that the infiltrating LysM-YFP ${ }^{+}$cells gave rise to fully differentiated resident macrophages. In contrast and more importantly, 
the $\mathrm{MHCII}^{\text {hi }} \mathrm{CX} 3 \mathrm{CR} 1^{-}$macrophages were not affected by the irradiation and remained present in the ME. This indicates that these cells are radio-resistant in nature what qualifies these cells to be involved in TLR3/TRIF signaling in POI. The reason for the difference in radio-sensitivity of MCHII ${ }^{\text {hi }} \mathrm{CX} 3 \mathrm{CR}^{-}$and $\mathrm{MCHII}{ }^{\text {hi }} \mathrm{CX} 3 \mathrm{CR} 1^{+}$immunocytes remains unclear. Maybe the different anatomical locations and morphologies $(9,45)$ play a role in the fate of these cells upon irradiation.

Our RNA-seq analyses provide further evidence on a distinct macrophage phenotype of the $\mathrm{MHCII}^{\mathrm{hi}} \mathrm{CX} 3 \mathrm{CR} 1^{-}$population. Gene expression patterns significantly differed and importantly CX3CR $1^{-}$cells showed a unique TLR gene expression signature with increased TLR3 and TLR11 expression levels, compared to $\mathrm{MHCII}{ }^{\mathrm{hi}} \mathrm{CX} 3 \mathrm{CR} 1^{+}$macrophages, which show increased levels of all other TLRs. While our RNA-seq analysis also detected higher transcript levels of the common DC markers CD103 and Flt3 in $\mathrm{MHCII}^{\mathrm{hi}} \mathrm{CX} 3 \mathrm{CR} 1^{-}$cells compared to their CX3CR1 ${ }^{+}$neighbors, we analyzed both populations by flow cytometry for presence of CD103, CD11b and CD11c. Notably, a previous study identified also a small population of resident $\mathrm{CD} 11 \mathrm{~b}^{+} \mathrm{CD} 103^{+} \mathrm{DCs}$ within the intestinal muscularis (46). However, only a very small percentage of MHCII ${ }^{\text {hi }} \mathrm{CX} 3 \mathrm{CR} 1^{-}$cells expressed the DC markers while the vast majority only stained positive for CD11b, confirming their myeloid origin.

In the last experimental setting, we demonstrated that MHCII ${ }^{\text {hi }}$ CX3CR1 ${ }^{-}$cells upregulate inflammatory cytokines upon IM, while the same population of TLR3 deficient mice failed to upregulate these cytokines. Although the cytokines tested in our study have been shown to play significant roles in POI $(7,32,33)$, they are not exclusively responsible for POI development. It should be noted that the absence of IL-6 expression in these cells was not observed in full $\mathrm{ME}$ specimens of intestinally manipulated $\mathrm{TLR}^{-/-}$compared to control mice (Figure 2). However, these data are not conflicting, as we have previously shown that enteric glial cells can also release IL-6 during POI (7). Unexpectedly, the CX3CR $1^{+}$cell population of TLR3 competent mice did not show an elevated inflammatory cytokine expression. However, under TLR3 deficiency, they expressed IL-6, IL-1 $\alpha$, and IL-1 $\beta$ upon IM. This indicates that under TLR3-deficiency, other pathways become activated and take part in the postoperative cytokine production. Furthermore, our data reflect only one time point and therefore we cannot completely exclude a role of TLR3 competent $\mathrm{CX} 3 \mathrm{CR} 1^{+}$cells in cytokine production at later time points in POI. Additionally, contribution of other radio-resistant cell types, known to express TLR3, e.g., enteric glial cells or neurons cannot be excluded. Conditional TLR3 knockout mice could provide clarity on the significance of TLR3 deficiency in any of these cells but these mice have so far not been available to us.

Finally, the question of the TLR3 ligand during POI still remains open. Since we were unable to detect dsRNA with a specific antibody by immunohistochemistry (clone J2, data not shown), we can only speculate on its source, which might be either viral, in the form of replication intermediaries from many enteral viruses (47), or cellular double-stranded secondary mRNA (e.g., hair pins) that may be released from necrotic cells. This cellular dsRNA was shown to induce a TLR3 dependent inflammatory cytokine production via the $\mathrm{NF}-\kappa \mathrm{B}$ activation in vitro (48). A possible involvement of this cellular dsRNA in POI pathogenesis is supported by the observed partially reduced ph-IKB levels in TLR3-deficient mice, which shows that ph-I $\mathrm{B}$ production is in part TLR3dependent. Also, a recent study from our group showed a role of DAMPs released in the early phase of POI (32). In another trauma model, upon irradiation, dying intestinal cells were also shown to release dsRNA that led to TLR3-dependent crypt cell death and gastrointestinal syndrome. Blockage of TLR3/dsRNA led to a reduction of cell death and an improvement with regard to gastrointestinal syndrome (15). Not only in the gastrointestinal tract but also outside of it in the skin dsRNA from damaged cells was shown to induce hair follicle regeneration via TLR3 (16). In contrast, a viral origin of dsRNA is supported by detection of microbial translocation upon intestinal surgery in mice $(11,12)$ and in humans (49). With more than $>10^{12}$ particles, bacteriophages represent the majority of human gut viruses (50). As they infect and reside within bacteria and can be released from them in response to stress signals (51), it appears not unlikely that they translocate within bacteria into the surgically manipulated ME.

In conclusion, this study reveals TLR3/TRIF signaling as a unique TLR pathway in the pathogenesis of POI, triggering inflammatory cytokine production in resident $\mathrm{MHCII}^{\text {hi }} \mathrm{CX} 3 \mathrm{CR}{ }^{-}$ IBA- $1^{+}$macrophages, which mainly colonize the deep myenteric plexus. Although further studies are needed to identify the source of dsRNA, this pathway is a promising new target for POI prevention.

\section{DATA AVAILABILITY STATEMENT}

The datasets presented in this study can be found in online repositories. The name of the repository and accession number can be found here: https://www.ncbi.nlm.nih.gov/, GSE132147.

\section{ETHICS STATEMENT}

The animal study was reviewed and approved by the governmental authority of North-Rhine Westfalia (LANUV).

\section{AUTHOR CONTRIBUTIONS}

JE, KJH, SM, RS, ML, BS, and SW performed the research. JE, $\mathrm{KJH}, \mathrm{SM}, \mathrm{RS}, \mathrm{KH}, \mathrm{BSch}, \mathrm{PG}$, JCK, and SW analyzed the data, and JE and SW prepared the manuscript. SW designed the research. JLS critically read the manuscript. All authors contributed to the article and approved the submitted version. 


\section{FUNDING}

This study was funded by the Deutsche Forschungsgemeinschaft (DFG, German Research Foundation) under Germany's Excellence Strategy - EXC 2151 - 390873048 and by a personnel grant of the German research council (DFG) to SW (WE4204).

\section{ACKNOWLEDGMENTS}

The authors thank Dr. Shizuo Akira (Osaka University, Osaka, Japan) for providing the $\mathrm{TRIF}^{-/-}$mice, Dr. Stefan Lienenklaus (Hannover Medical School, Hannover) for providing the

\section{REFERENCES}

1. Goldstein JL, Matuszewski KA, Delaney CP, Senagore AJ, Chiao EF, Shah M, et al. Inpatient economic burden of postoperative ileus associated with abdominal surgery in the United States. P\&T (2007) 32(2):82-90.

2. Boeckxstaens GE, de Jonge WJ. Neuroimmune mechanisms in postoperative ileus. Gut (2009) 58(9):1300-11. doi: 10.1136/gut.2008.169250

3. Kalff JC, Schraut WH, Simmons RL, Bauer AJ. Surgical manipulation of the gut elicits an intestinal muscularis inflammatory response resulting in postsurgical ileus. Ann Surg (1998) 228(5):652-63. doi: 10.1097/00000658199811000-00004

4. Wehner S, Behrendt FF, Lyutenski BN, Lysson M, Bauer AJ, Hirner A, et al. Inhibition of macrophage function prevents intestinal inflammation and postoperative ileus in rodents. Gut (2007) 56(2):176-85. doi: 10.1136/ gut.2005.089615

5. Engel DR, Koscielny A, Wehner S, Maurer J, Schiwon M, Franken L, et al. T helper type 1 memory cells disseminate postoperative ileus over the entire intestinal tract. Nat Med (2010) 16(12):1407-13. doi: 10.1038/nm.2255

6. Pohl JM, Gutweiler S, Thiebes S, Volke JK, Klein-Hitpass L, Zwanziger D, et al. Irf4-dependent CD103(+)CD11b(+) dendritic cells and the intestinal microbiome regulate monocyte and macrophage activation and intestinal peristalsis in postoperative ileus. Gut (2017) 66(12):2110-20. doi: 10.1136/ gutjnl-2017-313856

7. Stoffels B, Hupa KJ, Snoek SA, van Bree S, Stein K, Schwandt T, et al. Postoperative ileus involves interleukin-1 receptor signaling in enteric glia. Gastroenterology (2014) 146(1):176-87.e1. doi: 10.1053/j.gastro.2013. 09.030

8. Muller PA, Koscso B, Rajani GM, Stevanovic K, Berres ML, Hashimoto D, et al. Crosstalk between Muscularis Macrophages and Enteric Neurons Regulates Gastrointestinal Motility. Cell (2014) 158(2):300-13. doi: 10.1016/ j.cell.2014.04.050

9. Gabanyi I, Muller PA, Feighery L, Oliveira TY, Costa-Pinto FA, Mucida D. Neuro-immune Interactions Drive Tissue Programming in Intestinal Macrophages. Cell (2016) 164(3):378-91. doi: 10.1016/j.cell.2015.12.023

10. de Schepper S, Verheijden S, Aguilera-Lizarraga J, Viola MF, Boesmans W, Stakenborg N, et al. Self-Maintaining Gut Macrophages Are Essential for Intestinal Homeostasis. Cell (2018) 175(2):400-15.e13. doi: 10.1016/ j.cell.2018.07.048

11. Stein K, Hieggelke L, Schneiker B, Lysson M, Stoffels B, Nuding S, et al. Intestinal manipulation affects mucosal antimicrobial defense in a mouse model of postoperative ileus. PLoS One (2018) 13(4):e0195516. doi: 10.1371/ journal.pone.0195516

12. Snoek SA, Dhawan S, van Bree SH, Cailotto C, van Diest SA, Duarte JM, et al. Mast cells trigger epithelial barrier dysfunction, bacterial translocation and postoperative ileus in a mouse model. Neurogastroenterol Motility (2012) 24 (2):172-84, e91. doi: 10.1111/j.1365-2982.2011.01820.x

13. Kawai T, Akira S. The role of pattern-recognition receptors in innate immunity: update on Toll-like receptors. Nat Immunol (2010) 11(5):37384. doi: $10.1038 /$ ni. 1863
IFN-Bluc ${ }^{+/-}$mice, and Dr. Irmgard Förster (LIMES - Institute, University of Bonn, Bonn) for providing the Lys $\mathrm{M}^{\text {cre+ }}$; ROSA26 ${ }^{\text {LSL-eYFP }}$ mice as well as Prof. Andreas Schlitzer and Prof. Elvira Mass (LIMES, Bonn) for critical discussion of the manuscript. The authors are grateful for the support of the flow cytometry core facility of the University Hospital Bonn.

\section{SUPPLEMENTARY MATERIAL}

The Supplementary Material for this article can be found online at: https://www.frontiersin.org/articles/10.3389/fimmu.2020.581111/ full\#supplementary-material
14. Nishiya T, Kajita E, Miwa S, Defranco AL. TLR3 and TLR7 are targeted to the same intracellular compartments by distinct regulatory elements. J Biol Chem (2005) 280(44):37107-17. doi: 10.1074/jbc.M504951200

15. Takemura N, Kawasaki T, Kunisawa J, Sato S, Lamichhane A, Kobiyama K, et al. Blockade of TLR3 protects mice from lethal radiation-induced gastrointestinal syndrome. Nat Commun (2014) 5:3492. doi: 10.1038/ncomms4492

16. Nelson AM, Reddy SK, Ratliff TS, Hossain MZ, Katseff AS, Zhu AS, et al. dsRNA Released by Tissue Damage Activates TLR3 to Drive Skin Regeneration. Cell Stem Cell (2015) 17(2):139-51. doi: 10.1016/j.stem.2015. 07.008

17. Yamamoto M, Sato S, Hemmi H, Hoshino K, Kaisho T, Sanjo H, et al. Role of adaptor TRIF in the MyD88-independent toll-like receptor signaling pathway. Science (2003) 301(5633):640-3. doi: 10.1126/science.1087262

18. Alexopoulou L, Holt AC, Medzhitov R, Flavell RA. Recognition of doublestranded RNA and activation of NF-kappaB by Toll-like receptor 3. Nature (2001) 413(6857):732-8. doi: 10.1038/35099560

19. Muller U, Steinhoff U, Reis LF, Hemmi S, Pavlovic J, Zinkernagel RM, et al. Functional role of type I and type II interferons in antiviral defense. Science (1994) 264(5167):1918-21. doi: 10.1126/science.8009221

20. Lienenklaus S, Cornitescu M, Zietara N, Lyszkiewicz M, Gekara N, Jablonska J, et al. Novel reporter mouse reveals constitutive and inflammatory expression of IFN-beta in vivo. J Immunol (2009) 183(5):3229-36. doi: 10.4049/jimmunol.0804277

21. Jung S, Aliberti J, Graemmel P, Sunshine MJ, Kreutzberg GW, Sher A, et al. Analysis of fractalkine receptor CX(3)CR1 function by targeted deletion and green fluorescent protein reporter gene insertion. Mol Cell Biol (2000) 20 (11):4106-14. doi: 10.1128/MCB.20.11.4106-4114.2000

22. Clausen BE, Burkhardt C, Reith W, Renkawitz R, Forster I. Conditional gene targeting in macrophages and granulocytes using LysMcre mice. Transgenic Res (1999) 8(4):265-77. doi: 10.1023/A:1008942828960

23. Wehner S, Straesser S, Vilz TO, Pantelis D, Sielecki T, de la Cruz VF, et al. Inhibition of p38 mitogen-activated protein kinase pathway as prophylaxis of postoperative ileus in mice. Gastroenterology (2009) 136(2):619-29. doi: 10.1053/j.gastro.2008.10.017

24. Kalff J, Carlos T, Schraut W, Billiar T, Simmons R, Bauer A. Surgically induced leukocytic infiltrates within the rat intestinal muscularis mediate postoperative ileus. Gastroenterology (1999) 117(2):378-87. doi: 10.1053/ gast.1999.0029900378

25. Bray NL, Pimentel H, Melsted P, Pachter L. Near-optimal probabilistic RNAseq quantification. Nat Biotechnol (2016) 34(5):525-7. doi: 10.1038/nbt.3519

26. Soneson C, Love MI, Robinson MD. Differential analyses for RNA-seq: transcript-level estimates improve gene-level inferences. F1000Res (2015) 4:1521. doi: 10.12688/f1000research.7563.1

27. Love MI, Huber W, Anders S. Moderated estimation of fold change and dispersion for RNA-seq data with DESeq2. Genome Biol (2014) 15(12):550 doi: $10.1186 / \mathrm{s} 13059-014-0550-8$

28. de Schepper S, Stakenborg N, Matteoli G, Verheijden S, Boeckxstaens GE. Muscularis macrophages: Key players in intestinal homeostasis and disease. Cell Immunol (2018) 330:142-50. doi: 10.1016/j.cellimm.2017.12.009 
29. Wehner S, Engel DR. Resident macrophages in the healthy and inflamed intestinal muscularis externa. Pflugers Arch (2017) 469(3-4):541-52. doi: 10.1007/s00424-017-1948-4

30. Wehner S, Vilz TO, Stoffels B, Kalff JC. Immune mediators of postoperative ileus. Langenbeck's Arch Surg/Deutsche Gesellschaft Fur Chirurgie (2012) 397 (4):591-601. doi: 10.1007/s00423-012-0915-y

31. van Bree SH, Nemethova A, Cailotto C, Gomez-Pinilla PJ, Matteoli G, Boeckxstaens GE. New therapeutic strategies for postoperative ileus. Nat Rev Gastroenterol Hepatol (2012) 9(11):675-83. doi: 10.1038/nrgastro.2012.134

32. Hupa KJ, Stein K, Schneider R, Lysson M, Schneiker B, Hornung V, et al. AIM2 inflammasome-derived IL-1 $\beta$ induces postoperative ileus in mice. Sci Rep (2019) 9(1):10602. doi: 10.1038/s41598-019-46968-1

33. Wehner S, Schwarz NT, Hundsdoerfer R, Hierholzer C, Tweardy DJ, Billiar TR, et al. Induction of IL-6 within the rodent intestinal muscularis after intestinal surgical stress. Surgery (2005) 137(4):436-46. doi: 10.1016/ j.surg.2004.11.003

34. Schmidt J, Stoffels B, Moore BA, Chanthaphavong RS, Mazie AR, Buchholz $\mathrm{BM}$, et al. Proinflammatory role of leukocyte-derived Egr-1 in the development of murine postoperative ileus. Gastroenterology (2008) 135 (3):926-36, 936 e1-2. doi: 10.1053/j.gastro.2008.05.079

35. Piao W, Ru LW, Piepenbrink KH, Sundberg EJ, Vogel SN, Toshchakov VY. Recruitment of TLR adapter TRIF to TLR4 signaling complex is mediated by the second helical region of TRIF TIR domain. PNAS (2013) 110(47):1903641. doi: $10.1073 /$ pnas. 1313575110

36. Trinchieri G. Type I interferon: friend or foe? J Exp Med (2010) 207(10):205363. doi: 10.1084/jem.20101664

37. Yang $\mathrm{CH}$, Yue J, Fan M, Pfeffer LM. Interferon induces miR-21 through a STAT3-dependent pathway as a suppressive negative feedback on interferoninduced apoptosis. Cancer Res (2010) 70(20):8108-16. doi: 10.1158/00085472.CAN-10-2579

38. Malakhova OA, Kim KII, Luo J-K, Zou W, Kumar KGS, Fuchs SY, et al. UBP43 is a novel regulator of interferon signaling independent of its ISG15 isopeptidase activity. EMBO J (2006) 25(11):2358-67. doi: 10.1038/ sj.emboj.7601149

39. Price AE, Shamardani K, Lugo KA, Deguine J, Roberts AW, Lee BL, et al. A Map of Toll-like Receptor Expression in the Intestinal Epithelium Reveals Distinct Spatial, Cell Type-Specific, and Temporal Patterns. Immunity (2018) 49(3):560-75.e6. doi: 10.1016/j.immuni.2018.07.016

40. Barajon I, Serrao G, Arnaboldi F, Opizzi E, Ripamonti G, Balsari A, et al. Tolllike receptors 3, 4, and 7 are expressed in the enteric nervous system and dorsal root ganglia. J Histochem Cytochem (2009) 57(11):1013-23. doi: 10.1369/jhc.2009.953539

41. Buchholz BM, Bauer AJ. Membrane TLR signaling mechanisms in the gastrointestinal tract during sepsis. Neurogastroenterol Motil (2010) 22 (3):232-45. doi: 10.1111/j.1365-2982.2009.01464.x

42. Mikkelsen HB. Macrophages in the external muscle layers of mammalian intestines. Histol Histopathol (1995) 10(3):719-36.
43. Avetisyan M, Rood JE, Huerta Lopez S, Sengupta R, Wright-Jin E, Dougherty JD, et al. Muscularis macrophage development in the absence of an enteric nervous system. Proc Natl Acad Sci USA (2018) 115(18):4696-701. doi: 10.1073/pnas.1802490115

44. Mikkelsen HB, Huizinga JD, Larsen JO, Kirkeby S. Ionized calcium-binding adaptor molecule 1 positive macrophages and $\mathrm{HO}-1$ up-regulation in intestinal muscularis resident macrophages. Anat Rec (Hoboken) (2017) 300 (6):1114-22. doi: 10.1002/ar.23517

45. Mikkelsen HB. Interstitial cells of Cajal, macrophages and mast cells in the gut musculature: morphology, distribution, spatial and possible functional interactions. J Cell Mol Med (2010) 14(4):818-32. doi: 10.1111/j.15824934.2010.01025.x

46. Flores-Langarica A, Meza-Perez S, Calderon-Amador J, Estrada-Garcia T, Macpherson G, Lebecque S, et al. Network of dendritic cells within the muscular layer of the mouse intestine. Proc Natl Acad Sci USA (2005) 102 (52):19039-44. doi: 10.1073/pnas.0504253102

47. Son K-N, Liang Z, Lipton HL. Double-Stranded RNA Is Detected by Immunofluorescence Analysis in RNA and DNA Virus Infections, Including Those by Negative-Stranded RNA Viruses. J Virol (2015) 89 (18):9383-92. doi: 10.1128/JVI.01299-15

48. Karikó $\mathrm{K}, \mathrm{Ni} \mathrm{H}$, Capodici J, Lamphier M, Weissman D. mRNA is an endogenous ligand for Toll-like receptor 3. J Biol Chem (2004) 279 (13):12542-50. doi: 10.1074/jbc.M310175200

49. Schietroma M, Pessia B, Carlei F, Cecilia EM, de Santis G, Amicucci G. Laparoscopic versus open colorectal surgery for colon cancer: the effect of surgical trauma on the bacterial translocation. A prospective randomized study. Am J Surg (2015) 210(2):263-9. doi: 10.1016/j.amjsurg.2014.09.031

50. Shkoporov AN, Hill C. Bacteriophages of the Human Gut: The "Known Unknown" of the Microbiome. Cell Host Microbe (2019) 25(2):195-209. doi: 10.1016/j.chom.2019.01.017

51. Duerkop BA, Hooper LV. Resident viruses and their interactions with the immune system. Nat Immunol (2013) 14(7):654-9. doi: 10.1038/ni.2614

Conflict of Interest: SW and JCK receive royalties from Wolter Kluwer for contribution to the postoperative ileus section of the UpToDate library.

The remaining authors declare that the research was conducted in the absence of any commercial or financial relationships that could be construed as a potential conflict of interest.

Copyright $\odot 2021$ Enderes, Mallesh, Schneider, Hupa, Lysson, Schneiker, Händler, Schlotmann, Günther, Schultze, Kalf and Wehner. This is an open-access article distributed under the terms of the Creative Commons Attribution License (CC BY). The use, distribution or reproduction in other forums is permitted, provided the original author(s) and the copyright owner(s) are credited and that the original publication in this journal is cited, in accordance with accepted academic practice. No use, distribution or reproduction is permitted which does not comply with these terms. 